\title{
Juan Ginés de Sepúlveda frente a León de Castro: una carta inédita en defensa de su traducción latina de la Política de Aristóteles ${ }^{1}$
}

\author{
Ignacio J. García Pinilla²; Julián Solana Pujalte ${ }^{3}$
}

Recibido: 18 de octubre de 2016 / Aceptado: 17 de febrero de 2017

Resumen. En este artículo se edita y traduce un documento en forma epistolar desconocido hasta ahora. Contiene la respuesta de Juan Ginés de Sepúlveda a algunas críticas vertidas por León de Castro a la traducción latina de la Política de Aristóteles publicada por el primero en 1548. Además de ofrecer un nuevo ejemplo del helenismo en Castilla en el siglo XVI, permite conocer no solo los puntos de vista de ambos eruditos sobre pasajes controvertidos de la obra aristotélica, sino también nuevos detalles sobre la actividad filológica de Sepúlveda y los materiales en los que se apoyó.

Palabras clave: Juan Ginés de Sepúlveda; León de Castro; Aristóteles; Política, Traducción; Humanismo.

\section{[en] Juan Ginés de Sepúlveda against León de Castro: an unpublished letter in defence of his Latin translation of Aristotle's Politics}

\begin{abstract}
In this article a previously unknown document in epistolary form is edited and translated. It includes Juan Ginés de Sepúlveda's reply to the criticisms made by León de Castro concerning the former's translation of Aristotle's Politics, first published in 1548. Apart from giving new evidence of the Hellenism found in the 16th century Castile, this letter allows us to learn not only both scholars' points of view about some controversial passages from Aristotle's work, but also new aspects of Sepúlveda's philological methods and the materials on which he relied.
\end{abstract}

Keywords: Juan Ginés de Sepúlveda; León de Castro; Aristotle; Politics; Translation; Humanism.

Sumario. a. La figura de Juan Ginés de Sepúlveda; su trabajo como helenista y su traducción de la Politica; sus polémicas. b. La figura de León de Castro y su peso en Salamanca. c. Características y estructura del escrito. d. Materiales usados en la composición de la carta. e. Datación. f. El contenido de la carta. g. El manuscrito y criterios de edición. h. Edición y traducción.

Cómo citar: García Pinilla, I. J.; Solana Pujalte, J. (2017) Juan Ginés de Sepúlveda frente a León de Castro: una carta inédita en defensa de su traducción latina de la Política de Aristóteles, en Cuadernos de Filología Clásica. Estudios griegos e indoeuropeos 27, 163-195

1 Este artículo se inserta dentro del proyecto «Republicanismos, fiscalismos, regalismos. Adhesiones y disidencias en el pensamiento político hispánico de la alta Edad Moderna (siglos XV al XVII) ( HAR2013-45788-C4-3-P)».

2 Universidad de Castilla-La Mancha

Departamento de Filología Hispánica y Clásica

E-mail: ignacio.gpinilla@uclm.es

3 Universidad de Córdoba

Departamento de Ciencias de la Antigüedad y de la Edad Media

E-mail: ca1sopuj@uco.es 
La polémica sobre la que versa este trabajo la protagonizaron dos figuras fundamentales del helenismo español del s. XVI, Juan Ginés de Sepúlveda y León de Castro, a quienes la fortuna ha tratado de forma desigual. El primero, a pesar de haber sido identificado durante mucho tiempo como el adversario retrógrado de fray Bartolomé de las Casas, es hoy una figura bastante conocida; su peripecia vital ha sido objeto de atención reciente por los estudiosos y su obra en buena medida editada y estudiada. De León de Castro no puede decirse lo mismo: el único intento biográfico que se le ha dedicado remonta al siglo XIX y ninguna de las obras que editó ha vuelto a ver la luz; ni tampoco las que sabemos que quedaron manuscritas y hoy tenemos localizadas. Su figura es más conocida por su papel en la persecución de los hebraístas contemporáneos (Martín Martínez de Cantalapiedra, Gaspar de Grajal, fray Luis de León y Benito Arias Montano) que por sus propias obras.

A tenor de lo dicho, bastarán unas líneas para centrar las dos figuras enfrentadas en el asunto que aquí tratamos. En el caso de Sepúlveda, bastante mayor que Castro, con especial atención a algunas de las polémicas en las que había tomado parte y, dado el asunto que se trata en la carta, a su trabajo como helenista. En el caso de Castro, a su peripecia vital hasta el momento del escrito que se presenta y prescindiendo de la polémica contra los hebraístas, ya que esta última es muy posterior y totalmente desconectada del asunto que nos ocupa.

\section{a. La figura de Juan Ginés de Sepúlveda; su trabajo como helenista y su traducción de la Política; sus polémicas}

Sepúlveda (1489/90-1573) cursó estudios en la Universidad de Alcalá de Henares (1510-1513) y en el colegio de San Antonio de Sigüenza (1513-1515) antes de obtener plaza en el Colegio de San Clemente de Bolonia (1515-1523), donde pudo asistir a las clases de Pietro Pomponazzi y se doctoró en Artes y Teología ${ }^{4}$. Su excelente dominio del griego le valió la protección de Alberto Pío, príncipe de Carpi, alumno también de Pomponazzi, y, ya en Roma, la de Ercole Gonzaga y de los pontífices Clemente VII y Julio II, quienes le encargaron o fueron dedicatarios de sus primeras traducciones aristotélicas:

Parvi naturales: Libri Aristotelis quos vulgo latini parvos naturales appellant... Bononiae, per Hieronymum de Benedictis, 1522, 15 de mayo 5 .

4 Se sigue el esquema del artículo de Solana Pujalte (2012), donde podrá encontrarse una relación detallada de todas sus obras y ediciones y una bibliografía puesta al día hasta esa fecha. El trabajo biobibliográfico de referencia sobre Sepúlveda, a pesar del tiempo trascurrido, sigue siendo el de Losada (1949). Puede consultarse también Muñoz Machado (2012). A todo ello debe añadirse la edición crítica de su obra completa: Juan Ginés de Sepúlveda, Obras completas, Pozoblanco: Ayuntamiento, 1995-2013, 16 v., todos ellos con introducción filológica, histórica o jurídica, edición crítica y traducción. La única traducción latina de Aristóteles publicada en esta colección es la de la Política (vid. infra).

5 Pietro Alcionio había publicado en 1521 una traducción de esta y otras obras aristotélicas. Sepúlveda compuso unos Errata Petri Alcyonii in interpretatione libri Aristotelis de incessu animalium, para poner de relieve los errores cometidos por Alcionio en su traducción, que añadió en forma de cuadernillo preliminar a su traducción de los Parvi. Durante el proceso de confección del libro, Sepúlveda debió cambiar de opinión y suprimió el cuadernillo alterando el prefacio en el que se justificaba la edición de los Errata. Sobre los avatares de este opúsculo y la edición de Bolonia de los Parvi, vid. Solana Pujalte (2000). 
De generatione et interitu: Aristotelis Libri de generatione et interitu... Bononiae, per Hieronymum de Benedictis, 1523, 15 de mayo; Lipsiae, Nicolaus Faber, 1537.

De mundo: Aristotelis liber de mundo... Bononiae, per Hieronymum de Benedictis, 1523, 20 de agosto.

Alexandri Aphrodisiei commentaria in duodecim Aristotelis libros de prima philosophia... Romae, in aedibus Marcelli Silber, alias Franch, 1527, mense februario; Parisiis, ex officina chalcographica Ludovici Cyanei, sumptibus honestissimi viri Simonis Colinaei, 1536, mense Aprili; Venetiis, apud Hieronymum Scotum, 1544; Venetiis, apud H. Scotum, 1551; Venetiis, apud Hieronymum Scottum, 1561.

Meteorum libri IV: Lutetiae, Ioannes Parvus, 1532.

Desde 1529 a 1536 permaneció en Roma al servicio del cardenal Quiñones y en relación con italianos y españoles relevantes: altos eclesiásticos en la curia (Gian Matteo Giberti, Íñigo López de Mendoza, Francisco y Juan Álvarez de Toledo) y nobles (Juan y Alfonso Núñez de Guzmán, Luis de Ávila y Zúñiga). Fueron años fecundos de una producción polifacética: Cohortatio (1529) invitando a Carlos V a abanderar la guerra contra los turcos; De ritu nuptiarum et dispensatione (1531), sobre el matrimonio y su dispensa y en contra del divorcio de Enrique VIII de Catalina de Aragón; Antapologia (1532), polémica contra Erasmo en defensa de Alberto Pio, su protector de Carpi; Democrates (1535), diálogo en que se defiende la compatibilidad del oficio de las armas con el cristianismo. En 1536 fue nombrado cronista del Emperador, lo que supuso su regreso a España y su dedicación fundamental a la redacción de su extensa obra históriográfica (De rebus gestis Caroli $V$, De orbe novo, Historia de Felipe $I I)^{6}$. A pesar de ello, no dejó de publicar obras de otra índole: Theophilus (1538) sobre los límites de la obligación de respetar el secreto; De correctione anni mensiumque Romanorum (1546) sobre la reforma del calendario romano; Epistolarum libri VII (1557), auténtica reivindicación de su figura como humanista, filósofo y teólogo, e instrumento de difusión de sus ideas; De regno (1570) sobre la monarquía y el oficio de gobernar. No obtuvo permiso para publicar su Democrates secundus (1545), en el que defiende la legitimidad de la conquista y sometimiento de las Indias; sobre este asunto solo consiguió imprimir, en Roma y con ayuda de Antonio Agustín, una Apología del Demócrates (1550).

Su última gran aportación como helenista, publicada en 1548, fue su traducción latina de la Política de Aristóteles, enriquecida con escolios:

Aristotelis de Republica libri VIII interprete et enarratore Ioanne Genesio Sepulueda, Parisiis, apud Vascosanum, 1548; Coloniae Agrippinae, in officina Birckmannica, 1601; Matriti, ex officina Joachimi Ibarra, 1775; Obras Completas XVI,1. Traducción latina de la Política de Aristóteles. Est. preliminar, introducción filológica, edición crítica y traducción de M. Herrero de Jaúregui y F. Arenas-

6 Toda su obra histórica quedó inédita por propia voluntad. Vid. a este respecto Moreno Gallego - Solana Pujalte García Pinilla (2001). 
Dolz. Introducción histórica de J. Campos y Fernández de Sevilla, Pozoblanco, Ayuntamiento, $2013^{7}$.

No podemos calificar la calidad de su traducción anotada de la Ética a Nicómaco, cuyo último intento de publicación se produjo en 1565, pero que finalmente quedó inédita y actualmente se considera perdida ${ }^{8}$.

Aunque es un campo todavía bastante inexplorado, podemos afirmar que las traducciones aristotélicas de Sepúlveda han gozado de una difusión apreciable desde su publicación. Algunos importantes contemporáneos suyos las manejaron: Pietro Pomponazzi para su comentario del De sensu; Gaspar Cardillo de Villapando para la suya del De generatione; Girolamo Nigri, Paolo Giovio y Pier Vettori son testigos del aprecio del que gozaba su tradución de los Parvi Naturales y de Alejandro de Afrodisias en los círculos humanísticos italianos contemporáneos; Girolamo Agostino Valier y Francesco Patrizi da Cherso manejaron también esta última traducción de Alejandro. Pero sin duda su obra más conocida y comentada ha sido la traducción de la Política. Sabemos que la manejaron y apreciaron en el s. XVI Marc Antoine Muret (del que se conserva un ejemplar con sus propias anotaciones) y en el XVII Theodor Zwinger, Andreas Schott, Gabriel Naudé, Huber van Giffen (que la considera optima versio), Daniel Heinsius (que lo llama eruditissimus) y Pierre Daniel Huet, que la maneja con reservas; en el s. XVIII la mencionan en sus estudios bibliográficos Johann Albert Fabricius y Johann Heinrich Boecler; y en el XIX la manejan para sus respectivas ediciones críticas Johann Gottlob Schneider, Franz Susemihl, Otto Immisch y W. L. Newman, estos dos últimos en sus ediciones teubneriana y oxoniense, respectivamente; en el s. xx sigue recurriendo a ella J. Aubonnet ${ }^{9}$ y más recientemente la edición patrocinada por el Istituto italiano per la storia antica, aún inconclusa ${ }^{10}$.

También existen indicios de la difusión de sus traducciones aristotélicas en el ambiente universitario salmantino de la época: Juan de Junta tenía en su librería en 1565 treinta ejemplares de la Política ${ }^{11}$; Benito Boyer en la suya, también en 1565, uno de los Meteorum libri (Lutetiae, Ioannes Parvus, 1532) ${ }^{12}$ y Francisco Manzano en 1574 otro ejemplar de sus Alexandri Aphrodisiei commentaria in duodecim Aristotelis libros de prima philosophia ${ }^{13}$, obra de la que el mismo Boyer tenía también otro ejemplar en su almacén de Medina del Campo ${ }^{14}$.

7 Al estudio de la edición parisina y sus erratas hemos dedicado varios trabajos, y también al establecimiento de los libros griegos que le pertenecieron y fueron legados en su testamento: Solana Pujalte - García Pinilla (2011); Solana Pujalte - García Pinilla (2015); Solana Pujalte (en prensa).

8 Probablemente porque fue denunciada ante el Santo Oficio. La información disponible sobre lo ocurrido con su Ética se recopila en García Pinilla - Solana Pujalte (1996). Como han señalado Herrero - Arenas (2013: CXXXIX, nota 14) «sus referencias a la Ética en los escolios a la Politica permiten recuperar algunos fragmentos de esta traducción perdida. Cf. p. e. $1,1,2 ; 1,2,19 ; 3,12,11 ; 4,9,1 ; 4,10,7 ; 7,1,15$ ».

9 Un estudio pormenorizado de todo ello puede encontrarse en O. H. Green (1940), A. Coroleu (1996a, 1996b, 2009).

10 Bertelli - Moggi (2011-). M. Curnis en la «Storia del testo» (I: 42) hace especial hincapié en su interés: «Quella di Sepulveda è dunque la prima traduzione latina desunta da più esemplari greci (perduti, o comunque non identificati con nessuno dei testimoni superstiti), in cui la contaminazione delle fonti è parallela alla segnalazione di varianti e di correzioni».

11 Bécares (2007: 85, entrada 274) «Treynta aristótiles Política de Sepúlveda».

12 Bécares (2007: 125, entrada 314) «Un meteora Sepúlbeda».

13 «Metafisica de Alexandro Afrodiseo de a pliego en Veneçia año de quarenta y cuatro», Bécares (2007: 232, entrada 527). Vid. eds. supra.

14 «Un Alexander Afrodisiensis in prima filosofia, doce gruesos», Bécares (1992: 165, entrada 862). La parquedad 
Sepúlveda, hombre pagado de sí mismo y de firmes convicciones, no rehuyó nunca la polémica, ni incluso contra los más grandes: con Erasmo sobre asuntos teológicos y bíblicos; con Gasparo Contarini sobre astronomía y el calendario; con Hernán Núñez el Pinciano sobre la interpretación de algunos pasajes de Plinio el Viejo $^{15}$; con Gaspar Cardillo de Villalpando sobre doctrina aristotélica; con Melchor Cano sobre la interpretación de algunos pasajes del Nuevo Testamento; con Miguel de Arcos sobre teología moral y con Bartolomé de las Casas sobre la esclavitud natural de los indios y las justas causas de su dominio ${ }^{16}$. A esta serie se puede añadir la revelada en la carta que se ahora se edita.

\section{b. La figura de León de Castro y su peso en Salamanca}

La identificación del destinatario de esta carta con León de Castro (ca. 1512-1585) requiere una argumentación, porque el encabezamiento presenta una configuración extraña: el amanuense de Sepúlveda escribió, centrado y en dos líneas, «Genesius Sepulueda - Leoni S. D.», representando el guion un hueco deliberadamente dejado en blanco. Con otra tinta (aunque, al parecer, la misma mano) añadió «magistro N..» ${ }^{17}$. A nuestro entender, solo es posible la identificación de este magister Leo, experto helenista y profesor, con León de Castro, catedrático salmantino por esos años.

La vida de León de Castro, clérigo secular, está intensamente vinculada a Salamanca, ciudad en la que no solo nació, sino donde también desarrolló su actividad académica ${ }^{18}$. En la afamada universidad salmantina completó Castro sus estudios a la sombra del Comendador Griego, Hernán Núñez de Guzmán, también conocido como el Pinciano. Allí comenzó a explicar griego en 1533 y alcanzó los grados de licenciado y maestro en Artes en 1539, si bien fue en 1548 cuando se afianzó definitivamente, al obtener la sustitución de la cátedra de Retórica con motivo de la

de las noticias que proporcionan los inventarios nos impiden tener la certeza de la edición a la que podrían corresponder los 21 ejemplares que aparecen en el inventario de Matías Gast en 1575: «Veynte y un Aristotelis Politica» (Bécares, p. 200, entrada 706) u otros 3 ejemplares sin más detalles de la antes mencionada librería salmantina de Benito Boyer: «Un Aristotelis politica» (Bécares 2007: 124, entrada 294); «Un Aristotelis de Republica» (Bécares 2007: 124, entrada 295); «Una politica Aristotelis» (Bécares 2007: 150, entrada 1359), que podrían haber sido de la traducción de Sepúlveda.

15 Se tratará específicamente sobre esta polémica más abajo, cuando se hable del Pinciano como maestro de León de Castro.

16 Un estudio de las polémicas puede verse en Sepúlveda (2007: ciii-cxvi y ccciv-cccxiv). Las referencias a la correspondencia de Sepúlveda siempre se hacen por esta edición (=ep.)

17 La letra N. era usada en las ediciones de epistolarios para ocultar el nombre propio del destinatario o del remitente; en este sentido, parece incompatible con la presencia de «Leoni» a continuación. Cabe suponer que inicialmente Sepúlveda no recordaba la categoría de su adversario, por lo que dejó un espacio vacío para poder completarlo después. La posterior inclusión de «N.» debería haber tenido como consecuencia la supresión de «Leoni», por lo que la ausencia de tachado quizá se deba a un olvido. Por otra parte, «magistro N.»: implica que el documento no se elaboró para enviárselo a ese «Leo», sino que existía la intención de difundirlo más ampliamente. De hecho, como más adelante se verá, en los escolios manuscritos del propio Sepúlveda a su traducción de la Política hay una referencia a un aspecto tratado en esta polémica, aunque no se menciona el nombre de su adversario (vid. notas 50-51).

18 A pesar del importante papel que desempeñó en Salamanca, carecemos de una monografía aceptable sobre León de Castro. A lo largo de este trabajo se citan algunos de los escasos estudios que se le han dedicado. En cuanto a la fecha de nacimiento, habitualmente silenciada, sirva como referencia el documento publicado por Pinta Llorente (1935: 37): «En la ciudad de Salamanca, a tres días del mes de marzo de mil y quinientos y setenta y dos años, [...] pareció siendo llamado el maestro León de Castro [...] de edad de cerca de sesenta años...». 
jubilación de su maestro ${ }^{19}$. Poco más tarde, en octubre de 1549 , comenzó a regentar en propiedad una cátedra de prima de latín ${ }^{20}$.

Por aquellos años centrales del siglo, los estudios de latín, griego y retórica pasaban por un mal momento en Salamanca, hasta el punto de que en 1550 la Universidad encomendó a León de Castro que viajara a Alcalá de Henares en busca de docentes con garantías. Es en este período cuando parece que puede situarse la carta objeto de estudio y la polémica correspondiente. En 1555 León de Castro dio a luz una obra singular de su maestro Hernán Núñez de Guzmán, explícitamente destinada a la publicación póstuma: Refranes o proverbios en romance que nuevamente colligió y glossó el comendador Hernan Núnez, Salamanca: Juan de Cánova, 1555. Castro respetó escrupulosamente la voluntad de su maestro, a pesar del carácter irreverente de parte de las paremias (a menudo sustituidas o edulcoradas en ediciones posteriores) ${ }^{21}$. Más adelante, en 1560, Castro es nombrado, junto con los maestros Enríquez y Navarro, para hacer la reforma de la universidad ordenada por el rey. A partir de entonces su figura gana visibilidad y peso en el claustro universitario, y las polémicas y enfrentamientos en que participa se suceden ${ }^{22}$. Pero entre todos estos puntos de fricción, son los más recordados los que enfrentaron a León de Castro con los hebraístas de su época: por una parte, su enfrentamiento con Benito Arias Montano y su tarea de edición de la Biblia Regia ${ }^{23}$; y por otra, la polémica con fray Luis de León (amén de otros hebraístas), puesto que fue su denuncia la que acabaría llevando a este último a la cárce ${ }^{24}$. Estas polémicas ruidosas, además de ser bastante bien conocidas, son todas posteriores al escrito que nos ocupa, por lo que no es preciso exponerlas aquí detalladamente.

Aunque en 1576 se había jubilado de su cátedra y trasladado a Valladolid, seguía en plena actividad cuando, en octubre de 1585, murió repentinamente a consecuencia de una caída de su mula ${ }^{25}$. Publicó en vida tres obras sobre exégesis bíblica:

Commentaria in Esaiam Prophetam ex Sacris Scriptoribus Graecis et Latinis confecta adversus aliquot commentaria et interpretationes quasdam ex rabbinorum scriniis compilatas (Salamanca, 1570) ${ }^{26}$;

Apologeticus pro lectione Apostolica et Evangelica pro Vulgata D. Hieronymi, pro translatione Septuaginta Virorum proque omni ecclesiastica lectione contra earum obtrectatores (Salamanca, 1585) ${ }^{27}$; y

Commentaria in Oseam Prophetam ex veterum Patrum scriptiis, qui Prophetas omnes ad Christum referunt (Salamanca, 1586) ${ }^{28}$.

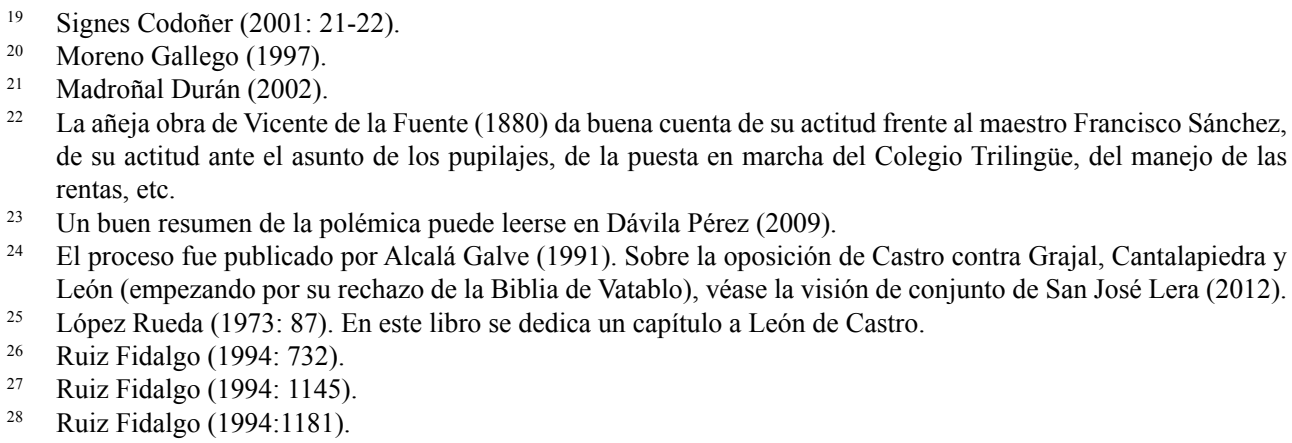


Consta, por último, que había solicitado licencia para publicar otras dos obras exegéticas y una tercera de carácter más apologético, que finalmente no llegaron a la imprenta ${ }^{29}$.

Pocas personas han suscitado tanta unanimidad como León de Castro a la hora de recibir calificaciones negativas. Alejandro Arango y Escandón menciona la «índole áspera y absoluta» de León de Castro, al que presenta como «hombre violento, descontentadizo, muy amigo de su propio dictamen $»^{30}$. Menéndez y Pelayo lo describe como un «hombre de genio iracundo y atrabiliario, muy pagado de su saber y muy despreciador de lo que no entendía $\rangle^{31}$; Vicente de la Fuente dice de él, que era «de carácter sombrío, oscuro, suspicaz y bronco», y como corolario, que «es el tipo de escolástico melancólico, bilioso, suspicaz, envidioso e intolerante» ${ }^{32}$. Pinta Llorente lo describe como «atrabiliario y áspero» ${ }^{33}$. López Rueda afirma que era «codicioso, acomodaticio y capaz de contradecirse en poco tiempo, según su conveniencia» y «hombre docto... pero intrigante y envidioso» ${ }^{34}$. Domínguez Domínguez lo tilda recientemente de «hombre de carácter visceral, aparte de su fatua jactancia» ${ }^{35}$. Estos juicios tan negativos se fundan en palabras de algunos de sus contemporáneos, que le dedicaron invectivas nada ligeras, como el humanista Pedro Chacón, con motivo de su actuación contra Arias Montano y la Biblia Poliglota de Amberes, o como la de su antiguo discípulo y amigo Juan del Caño ${ }^{36}$.

Para el aspecto que aquí nos ocupa, el de su dominio de Aristóteles, resulta interesante la indicación de Domínguez Reboiras de que, a pesar de las décadas que pasó enseñando latín, griego y retórica en la universidad salmantina, no nos ha legado una sola línea al respecto ${ }^{37}$. Sin embargo, si el escrito de Sepúlveda que ahora presentamos corresponde a otro previo de León de Castro, sería el primer testimonio, aunque perdido, de algo escrito por él y con contenido directamente relacionado con su actividad académica; podría tratarse de uno de los escasos testimonios contemporáneos sobre su calidad académica como profesor de griego ${ }^{38}$.

Para la cabal comprensión de la carta que aquí se edita es preciso tener en cuenta que Sepúlveda había mantenido entre 1544 y 1545 una agria polémica con Hernán Núñez de Guzmán, maestro de León de Castro. Esta polémica puede reconstruirse gracias a varias cartas incluidas años después en los Epistolarum libri VII del

\footnotetext{
29 De todas ellas da noticia Rojo Vega (1997).

30 Arango y Escandón (1856: 15-16).

31 1992: II, p. 419.

$32 \quad 1880: 49$ y 78.

33 1935: X.

34 1973: 76 y 315. Buena parte de estas perlas las recopila Moreno Gallego (1997: 57).

35 Domínguez Domínguez (2013).

36 Respecto al primero, vid. Domínguez Domínguez (2013: 203-244). Chacón comienza afirmando que el ataque de León de Castro pone en duda «la cristiandad, celo, doctrina y juicio» de este, quien «se deja llevar tanto de la pasión y se abalanza tan sin orden a herir al contrario, que sin hacer reparo alguno descubre el cuerpo todo...» (ibid., líneas 14-18); y de su modo de proceder dirá que es «como viejo marrullero y ladrón de su casa» (ibid., línea 123). Respecto al segundo, vid. Domínguez Domínguez (2015). En 1575 Caño le espeta por carta: «V. m. es uno de los más impetuosos y furibundos hombres que hay en España en lo que afierra, y fuelo así siempre; [...] en tanto grado, que no hay león africano tan furioso» $(2015: 221)$.

37 Domínguez Reboiras (1988: 186-187).

38 Otro testimonio se recoge en Domínguez Reboiras (1988: 190), allí se mencionan unas palabras de Martín Martínez de Cantalapiedra en las que denunciaba el escaso conocimiento de lenguas del maestro Castro: «la lengua hebraica, la cual nunca él [León de Castro] supo [...], ni la griega, sino muy poco», tomado del Proceso de Martín Martínez de Cantalapiedra, f. 103r.
} 
humanista de Pozoblanco ${ }^{39}$. La disensión entre los dos sabios, favorecida por el carácter de ambos, existía larvada al menos desde 1542, cuando Sepúlveda escribió al Pinciano señalando algunos puntos débiles de su edición de Pomponio Mela. La desavenencia se manifestó abiertamente en 1544, a raíz de una carta de Sepúlveda en la que de nuevo manifestaba algunas discrepancias en la interpretación de algunos pasajes de Plinio, la siguiente edición del Pinciano, en la que este último había estado trabajando durante muchos años. El tono de las cartas que se cruzaron fue subiendo, por lo que el encuentro que pocos meses después tuvieron ambos humanistas en Salamanca no sirvió mas que para enconar las heridas. Quizá León de Castro viera en la traducción sepulvediana de la Política la ocasión de pagar con la misma moneda a quien tanto había irritado a su maestro. Ahora bien, entre la polémica de 1544 y la publicación de la traducción de la Política en 1548 se sitúa la publicación de otra obra de Sepúlveda, el De correctione anni mensiumque Romanorum, y, sin embargo, no consta que este librito fuera objeto de ataques en Castilla. En este sentido, quizá deba tenerse en cuenta que esa pequeña obra se publicó en Venecia (1546) y París (1547), lo que quizá dificultó que llegara hasta Salamanca, de modo que quizá fuera desconocida para León de Castro. Aparte de la posibilidad de que la crítica de este último tenga un cierto carácter de venganza, cabe preguntarse si las correcciones contra las que responde Sepúlveda procedían únicamente del ingenio de aquel o si sería más apropiado ver detrás también el dedo acusador de Hernán Núñez de Guzmán. En contra de esta última hipótesis está que Sepúlveda en ningún momento manifiesta sospecha alguna en este sentido.

Como último argumento a favor de la identificación del destinatario con León de Castro puede señalarse que no conocemos ningún otro helenista con grado de maestro, que estuviera geográficamente cerca de Sepúlveda (commodius poterat coram explicari, dice en la carta) y cuyo nombre incluyera la palabra León ${ }^{40}$. De todos modos, Castro no aparece mencionado en ninguna ocasión en el epistolario de Sepúlveda, por lo que esta carta descubre una relación epistolar de la que hasta ahora nada sabíamos.

\section{c. Características y estructura del escrito}

El documento ahora editado consiste en la defensa de Sepúlveda, en forma de respuesta epistolar, de sus De Republica libri VIII, frente a un escrito previo del maestro León, en el que se criticaban algunos pasajes de su obra. Como no ha llegado a nosotros ese escrito, el conocimiento de la polémica se limita al punto de vista de uno de los contendientes.

Al redactar su respuesta, Sepúlveda pasa revista a seis críticas del maestro León, sin que podamos saber si con ello respondía a todas las objeciones o solo a algunas. En cualquier caso, en ningún momento reconoce que su crítico haya realizado alguna aportación aceptable. En cada una de esas críticas (salvo en la que afecta a la interpretación de un solo término, $\delta \eta \mu \alpha \gamma \omega \gamma o ́ s)$ procede de un modo similar, por

39 Son las cartas 51, 52, 55, 56 y 57, todas ellas dirigidas por Sepúlveda al Pinciano.

40 Parece que puede descartarse a Sebastián de León, que durante un tiempo indeterminado sirvió a Sepúlveda como secretario, con quien siempre mantuvo una relación cordial, y que nunca fue magister, vid. Solana Pujalte (2016). 
lo que es posible indicar un esquema organizativo. Fuera de este esquema, que a continuación se expone, quedan unos escuetos párrafos de introducción y despedida.

Primeramente, Sepúlveda introduce cada sección con un encabezamiento tripartito: este consta de la referencia de libro y capítulo, más el texto griego objeto de debate, tras el que se aporta la traducción latina incluida en De republica libri VIII. Después del encabezamiento comienza la argumentación, en la que primeramente expone, mediante paráfrasis o explicación, el contenido del pasaje debatido. Para ello, cuando es preciso, acude a textos paralelos o complementarios de Aristóteles, tomados de la misma o de alguna otra de sus obras. Finalmente, descalifica la propuesta de su crítico por ser incompatible con el sentido del texto o con el conjunto de la doctrina aristotélica. En esta secuencia de desarrollo, en ocasiones Sepúlveda reproduce, de modo más o menos literal, los argumentos de su adversario; ahora bien, como los usos de puntuación de la época no dejaban constancia de la cita literal, a veces son inciertos los límites de una de estas citas o su carácter realmente literal; un ejemplo de ello podía ser la frase:

Porro quod ipse pro «civili imperio, quo rex fungitur», «urbanos magistratus» interpretaris, quam probe conveniat cum Aristotelis sensu viderint doctiores ${ }^{41}$.

Casi todas las apariciones del término ipse son como sujeto de un verbo en segunda persona y corresponden al destinatario, el maestro León. En el ejemplo superior, la información implicada es que este último había escrito interpretando un término (civile imperium) en un sentido (urbani magistratus) que es, para Sepúlveda, inaceptable.

La crítica de Sepúlveda, en los seis pasajes, se atiene al método filológico tal como se concebía en la época. Se sirve de la comparación con lugares similares en busca de la similitud interna y externa; también hay en un caso un argumento gramatical, y en otra ocasión se acude a los manuscritos, cuya unanimidad Sepúlveda se muestra reacio a violar, como propone su adversario. También se apoya en su profundo conocimiento de la filosofía aristotélica para mostrar la coherencia o incoherencia del sentido propuesto. Por último, cuando lo juzga oportuno acude a otras fuentes, tanto griegas como latinas.

\section{d. Materiales usados en la composición de la carta}

En concreto, ¿de qué materiales textuales se sirvió Sepúlveda en su defensa? En términos generales, los mismos que usó para su De republica. En concreto, para el texto griego usó como base la edición de Aristóteles publicada en Venecia por Aldo Manuzio entre 1495 y 1498, tal como se repite en varias ocasiones en los escolios a la obra ${ }^{42}$, refiriéndose a ella como exemplar Aldinum, vulgata editio y, en esta carta, codex ab Aldo excusus. A veces menciona los vulgati codices, aquellos en los que

${ }^{41}$ El único caso en que la cita literal parece neta es este: «"Populares», inquis, «homines” Cicero solet nominare qui populo placere student, non "duces populares"», et nos scilicet ignorabamus... (§ 18).

42 De rep. 3,3,30; 5,1,14 ... Las referencias a su traducción latina de la Política se hacen siguiendo la edición de Herrero - Arenas (2013) ( = De rep.), salvo que por alguna razón quiera hacerse mención a la edición príncipe de 1549 . 
Aldo se basó para su edición, pero de cuya consulta directa por Sepúlveda no hay constancia.

También cita esporádicamente la traducción latina de la Política de Guillermo de Moerbecke (1215-1286), difundida exclusivamente por vía manuscrita; a ella se refiere como vetus traslatio, y a su autor como interpres o vetus interpres ${ }^{43}$.

Por otra parte, Sepúlveda tuvo acceso a varios códices griegos de la Política durante su estancia en Roma; así lo menciona en los escolios a De republica y en la carta que ahora editamos ${ }^{44}$. Se refiere a ellos como emendatiora manuscripta, codices emendati/ castigati $^{45} \mathrm{o}$ vetusti/antiqui ${ }^{46}$, pero no aporta ningún dato más sobre ellos. También en esta carta se remite en una ocasión a ellos, y los llama [codices] vetustissimi.

Entre el material legado testamentariamente por Sepúlveda a la biblioteca de la catedral de Córdoba, se conserva el referido ejemplar aldino, jalonado por centenares de notas críticas en las que se da noticia de la lectura que presentan, al menos, cuatro manuscritos y la traducción de Guillermo de Moerbecke ${ }^{47}$. Se trata de un auténtico cuaderno de trabajo sobre el que Sepúlveda va anotando las diferentes variantes en cada pasaje discutido. Sin adelantar las conclusiones del trabajo que estamos llevando a cabo, podemos señalar que hemos identificado uno de estos manuscritos; se trata del Vaticanus Urbinas Graecus 46, que perteneció al duque Federico de Montefeltro ${ }^{48}$. Cuando en el ejemplar aldino de Sepúlveda haya anotaciones manuscritas referidas a alguno de los pasajes discutidos en la carta, haremos referencia a ellas.

Por último, como apoyatura para sus argumentos acude ocasionalmente en esta carta a la autoridad de Cicerón y de san Jerónimo; el primero está presente en los escolios a su De republica, pero no así el segundo.

\section{e. Datación}

La carta se escribió con seguridad después de la publicación de la traducción en 1548. Aunque a veces los humanistas daban a leer sus obras todavía inéditas a algún amigo para recabar su opinión, no parece que este sea el caso ${ }^{49}$. En efecto, no es verosímil que Sepúlveda enviara a León de Castro su traducción, completa o en parte, antes de ser publicada, porque de este último no hay referencia ninguna que permita considerarlo su amigo, y sí hay, en cambio, argumentos para suponer que podría tener al menos cierta prevención hacia él.

Para la datación debe considerarse más concluyente otro hecho; en una de las notas manuscritas añadidas por el propio Sepúlveda al margen de un par de ejemplares de

$43 \quad$ De rep. $1,1,18 ; 1,2,12 ; 3,3,30 \ldots$

44 «Meus enim quem secutus sum codex ab Aldo excusus cum quattuor manu scriptis vetustissimis Romae collatus fuit et emendatus; quae omnia exemplaria et quod secutus est vetus interpres hoc in loco consentiunt» (§ 16).

45 De rep., praef. 6; Schol. 1,2,12;1,4,12;1,6,18; 2,1,5;2,3,17; 2,4,33; 2,9,15; 5,1,14; 5,8,17; 5,8,34; 5,9,11; $5,10,20 ; 6,1,4$.

$46 \quad$ De rep. $1,3,3 ; 1,3,4 ; 1,4,7 ; 1,6,18 ; 2,3,8$.

47 La existencia del ejemplar es conocida al menos desde la publicación del catálogo catedralicio de manuscritos e incunables, vid. García - Cantelar - Nieto (1976) y Nieto Cumplido (1979). A pesar de ello no ha despertado el interés de los investigadores. Nosotros lo estudiamos desde hace varios años y esperamos publicar sus notas críticas en breve. Un anticipo en Solana Pujalte (en prensa).

48 Stornajolo (1895: 46).

49 Sepúlveda, por ejemplo, envió a Contarini en 1539 un borrador de su De correctione anni mensiumque Romanorum para conocer su opinión antes de publicarlo (ep. 43). 
su De republica ${ }^{50}$, destinadas a una segunda edición de la obra, dejó constancia de uno de los pasajes discutidos aquí (1290b 9-11), refrendando su opinión y criticando la de León de Castro, a quien se refiere sin nombrarlo bajo las palabras quidam vir doctus meus amicus. Se trata del siguiente pasaje:

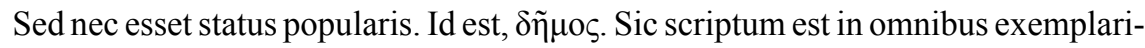
bus Graecis quae mihi videre contigit. Si quod tamen pro $\delta \tilde{\eta} \mu \circ \zeta$ haberet ỏ $\lambda ı \gamma \alpha \rho \chi i \alpha$, commodior sensus videretur, ne bis idem exemplum repeteretur in eodem capite. Nam quod supra dixit «Si essent omnes mille trecenti» et cetera eumdem sensum habet quem haec oratio: «Sed nec status popularis» et cetera. In exemplo enim superiore proximoque si quis pro $\delta \tilde{\eta} \mu \circ \varsigma_{\text {reponeret }} \lambda \lambda \gamma \alpha \rho \chi i \alpha$, ut facere quidam vir doctus meus amicus censebat, sensum corrumperet. Esset enim eiusdem exempli inepta repetitio in eodem capite, cum eumdem sensum habeant verba illa: «Si pauci essent egeni» et cetera. Illud autem certum est, neutrum locum posse falsi convinci, aut inconstantiae, quasi aliquid habeat abhorrens ab Aristotelis doctrina, ut contra fidem consentientium exemplarium aliquid mutare, studii magis rerum novarum, quam gravitatis esse videatur ${ }^{51}$.

Parece claro, en consecuencia, que se trata de una reflexión posterior a la edición del texto, pues en caso contrario Sepúlveda la habría incorporado en forma de escolio directamente a la edición parisina. Postulamos, por tanto, una datación de la carta algo posterior a la publicación de la obra, no antes de 1549 , pero tampoco muy alejada de esta fecha ${ }^{52}$. Consta que Sepúlveda ya tenía confeccionada una lista de erratas en febrero de 1554 , pero no se dice expresamente que incluya ampliaciones y retoques de los escolios ${ }^{53}$.

\section{f. Contenido de la carta}

0. León ha criticado con precipitación y sin fundamento algunos presuntos errores de su traducción de la Política de Aristóteles, y por eso Sepúlveda le responde. Pasajes discutidos.

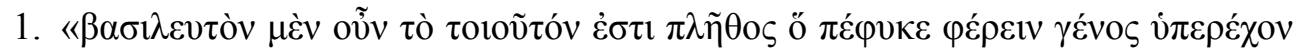

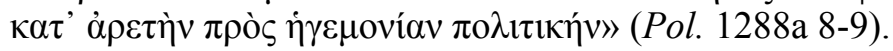

«Haec igitur multitudo regno est accommodata quae natura est habilis, ut ferat genus virtute praestans ad ciuilem principatum» (De rep. 3,12,7, 8-9 $)^{54}$.

50 Las hemos estudiado en Solana Pujalte - García Pinilla (2011); Solana Pujalte - García Pinilla (2015).

51 Solana Pujalte - García Pinilla (2015: 1029-1030).

52 El privilegio de impresión está datado en París el 18 de febrero de 1548, pero parece que en verano todavía no habían concluido los trabajos de impresión, cf. Epistolario, carta 69. Si la impresión hubiese comenzado inmediatamente después, habría que dejar pasar unos meses para que el libro llegase a Salamanca, algunos otros para la lectura que León de Castro hizo de la obra y la redacción de la primera carta, el envío y la redacción de la respuesta de Sepúlveda.

53 Epistolario, carta 112.

54 Las citas de la traducción latina de Sepúlveda, incluidas por él mismo en la carta, pueden verse en edición moderna en Herrero - Arenas (2013). 
«Está dispuesto a la monarquía el pueblo aquel que de forma natural produce una raza que sobresale por su virtud en orden a la dirección política» ${ }^{55}$.

Se trata de lo que dispone a un pueblo para un determinado tipo de gobierno. La interpretación del pasaje es que un pueblo está orientado a la monarquía si hay una familia digna, por sus cualidades eminentes, para estar al frente del orden político. El poder puede ser político o despótico; el primero puede ser ejercido tanto por un príncipe como por una familia que destaque por sus cualidades y trate al pueblo como ciudadanos.

Sepúlveda objeta, por otra parte, la interpretación que Castro hace del civile imperium (quo rex fungitur) como urbanum magistratum. Esta última expresión se usa por contraste con magistratus municipales o agrestes (libro VII): 7,12 = 1331b 5

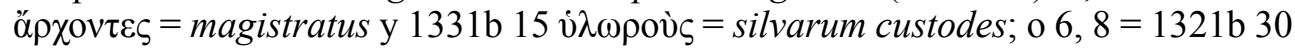
silvarum inspectores; o 6, $8=1321 \mathrm{~b} 30$ y 7, $12=1331 \mathrm{~b} 15$ à $\gamma \rho$ ovó $\mu \mathrm{ov} \varsigma=$ praefectos agrorum. Es decir, sería incorrecto entender que cuando Aristóteles habla de civile imperium se está refiriendo a un urbanum magistratum.

Por último, ante el comentario de Castro de que la virtud de un buen ciudadano y de una persona buena son lo mismo, Sepúlveda matiza que es así, pero Castro lo ha aplicado mal en su crítica del pasaje. Tras virum virtute praestantem Castro propone traducir qua possit civiliter imperare; ahora bien, si tal interpretación fuera correcta, sería superfluo el segundo elemento; si en el pasaje se especifica es porque el mando que ejerza alguien sobresaliente en virtud no siempre es político, sino que puede ser

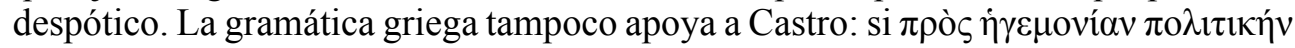

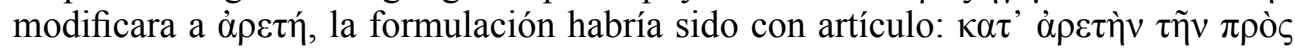

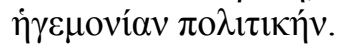

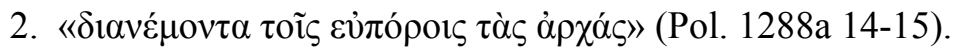

«divitibus magistratus mandantur» ( De rep. 3,12,7,13).

«reparte... los cargos a los ricos».

León de Castro defiende que debe editarse àđóporৎ («para los pobres»), ya que, según él, en la llamada comúnmente $\pi$ o $\lambda \imath \tau \varepsilon i ́ \alpha$ (respublica) el poder pertenece a los pobres. Sepúlveda, por contra, alega que en Aristóteles esa forma de gobierno es

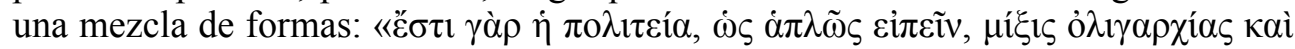
$\delta \eta \mu о к \rho \alpha \tau \mid \alpha \varsigma » ~(1293 b, 33-34)$. «Est enim Respublica, ut simpliciter loquar, quaedam ex paucorum potentia et statu populari temperatura» (De rep. 4, 8,1,11-12).

En estas palabras de Aristóteles se muestra palmariamente que, en la república surgida de la unión de ricos y pobres, se han de confiar las magistraturas especialmente a los ricos, que disponen de tiempo libre y virtud, pero con el voto de los pobres, por los cuales tendrían que ser también revocados/corregidos. Es decir, en la república las magistraturas se encomiendan a los ricos con el voto de los pobres. Castro confunde multitudo (o sea, populus) con pauperum turba; ahora bien, el primero de estos conceptos consta tanto de ricos como de pobres. Escribir que en la comúnmente llamada república el poder reside en los pobres es convertir a la república en una

55 Las traducciones castellanas de los textos aristotélicos están tomadas de García Gual - Pérez Jiménez (1986). 
democracia (status popularis), que se define precisamente por esto en el libro 4 capítulo 4, porque en él la masa de pobres tiene el poder ${ }^{56}$.

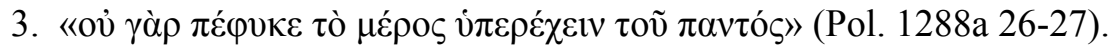

«natura, quae partem toti praeferri non sinit, repugnante» (De rep. 3,12,8, 24-25). «no es natural que la parte se ponga encima del todo».

Para Castro a la ciudad se le llama «todo» y a un hombre tan insigne por su virtud se le llama «una parte»; para Sepúlveda, el ciudadano destacado es el «todo» y cualquier otro ciudadano es la «parte». Pues cualquiera de la ciudad que fuera antepuesto y mandara a este, al igual que a los demás, sería como parte de este, porque la virtud de este engloba y supera las virtudes de todos los demás, de modo que la virtud de cualquier ciudadano, comparada con la de este, parezca que es una parte mínima de ella. Sepúlveda reconoce que el pasaje es ambiguo, lo que es motivo para no censurar a quien discrepe, como hace Castro.

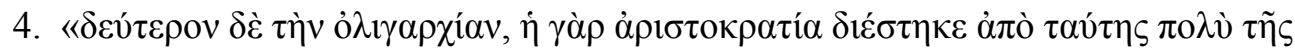

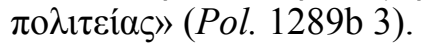

«Proxime ab hac paucorum dominatum, quippe a quo longissime optimatum administratio abest» (De rep. 4,2,2, 18-19).

«y en segundo lugar la oligarquía (pues la aristocracia dista mucho de este régimen)».

El sentido que le da Sepúlveda es este: así como la tiranía es la peor forma de gobierno de todas, pues se contrapone a la monarquía (que es la mejor de todas), así también la oligarquía es la segunda más desviada, porque se contrapone a la aristocracia (que ocupa el puesto siguiente a la monarquía entre las formas rectas). Por lo tanto, la oligarquía es la forma de gobierno más cercana a la tiranía. Es insostenible la opinión de Castro de que según el texto la aristocracia se aparta mucho de la monarquía, pues en realidad Aristóteles las considera cercanas y estrechamente vinculadas entre sí.

Castro acusa a Sepúlveda de no haber referido las palabras finales de esa cita a la oligarquía y a la aristocracia. Sin embargo, tanto en la traducción como en los escolios es evidente lo contrario (Schol. in 4,2,1).

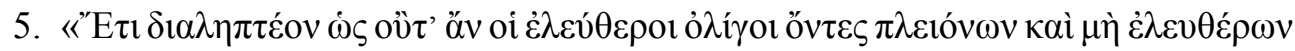

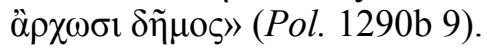

«Statuere oportet non protinus esse statum popularem, si liberi homines pauci in numero in plures et non liberos imperium teneant» (De rep. 4,4,2, 18-20).

«Se ha de especificar además que ni aunque los libres, siendo pocos, manden sobre muchos y no libres, tendremos democracia».

56 Además de la explicación que Sepúlveda deduce de la interpretación del propio texto, hay razones de crítica textual que avalan esta variante, especialmente la traducción que hace del pasaje Guillermo de Moerbecke en su traducción literal de un códice griego anterior al s. XIII, hoy perdido; traducción que, en palabras de F. Susemihl (1872: VI) «tam fideliter et accurate verbum pro verbo reddens, ut raro quid in illo codice suo legerit dubitare queas». En este punto, la traducción de Moerbecke dice: «distribuentem principatus secundum dignitatem opulentis» (ibid.). 
Sepúlveda rebate la crítica de Castro, quien defiende que en este pasaje había que sustituir $\delta \tilde{\eta} \mu \circ \varsigma$ por ỏ $\lambda$ i $\gamma \alpha \rho \chi i \alpha$. Rebate la propuesta con argumentos conceptuales y de crítica textual. Conceptualmente es coherente esa afirmación con las formas políticas definidas por Aristóteles, ya que solo puede haber democracia cuando hay una mayoría de hombres libres y pobres que gobiernan; al no afirmarse si son o no pobres y ser pocos, no puede haber democracia, sino una forma que rara vez se produce. Para que hubiera oligarquía (opinión sostenida por Castro), tendría que haber un gobierno de pocos y ricos, lo que no dice el texto. Tampoco es defendible el cambio por razones textuales, ya que ningún testimonio aporta esa lectura.

Por último, tampoco acepta Sepúlveda que para Aristóteles en este lugar «democracia» sea no aquella forma de gobierno degenerada que suele señalarse con este nombre, sino toda clase de gobierno en que el mando absoluto está en manos del

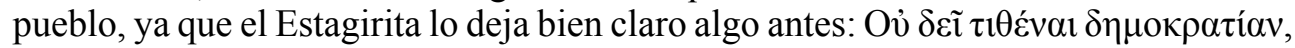

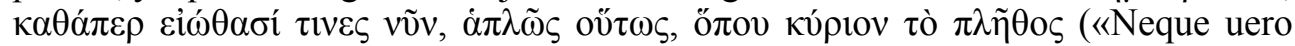
debet, ut a quibusdam solet, democratia simpliciter statui, ubi summa potestas est penes multitudinem») $)^{57}$.

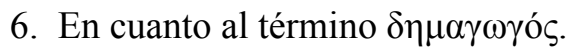

Justifica Sepúlveda su traducción del término $\delta \eta \mu \alpha \gamma \omega \gamma o ́ \varsigma$ por duces populares y adulatores populares aduciendo los usos del término popularis en Cicerón y el sentido del vocablo en Aristóteles. Ha buscado acercarse al sentido literal del término en el Estagirita y también a la buena latinidad.

Conclusión: Castro ha difundido un juicio negativo sin haber estudiado a fondo la cuestión; es una actitud reprochable, pero Sepúlveda no quiere darle más importancia.

\section{g. El manuscrito y criterios de edición}

La carta está contenida en un manuscrito misceláneo que probablemente perteneció a la biblioteca del erudito italiano Ottavio Falconieri (1636-1675), antes de ser adquirido por Frederick North, V conde de Guilford, y con posterioridad por la British Library (Add Ms 8289) ${ }^{58}$. Reúne documentación en italiano, latín y griego sobre temas variados, en especial sobre historia de la Iglesia. Cuenta con $366 \mathrm{ff}$ y unas dimensiones de 328 x $237 \mathrm{~mm}$. El ms. presenta dos textos de autores españoles: ff. 167176 («Index variarum epistolarum summorum pontificum», reunido por García de Loaysa) y ff. 259-263v (la carta de Sepúlveda que estudiamos). Desconocemos cómo este último documento pudo llegar a formar parte de esa colección.

La letra de esta última pertenece a uno de los amanuenses habituales del humanista cordobés, y la de los textos en griego es la del propio Sepúlveda, tal como sucede en otros manuscritos del autor ${ }^{59}$. El documento no presenta señales de haber sido enviado como una verdadera carta, pero tampoco se trata de una minuta, pues no presenta vacilaciones de redacción ni tachados, mejoras, etc. Su factura recuerda

57 Pol. 1290a30, De rep. 4,4,1, 1-2. «Pero no debe establecerse, como algunos suelen hacer, que hay democracia sin más donde la masa tiene la potestad suprema».

58 Esta información procede de la descripción del manuscrito en la web de la British Library.

59 Solana Pujalte - García Pinilla (2011: 296). Hemos consultado el ms. a través de una reproducción digital amablemente proporcionada por la British Library. 
en rasgos generales a los documentos (contemporáneos, por cierto) de la polémica de Sepúlveda con Melchor Cano, que también tienen forma de carta y de los que tampoco consta que fueran enviados como tal. La diferencia entre ambas estriba en que en la dirigida a León de Castro la despedida finaliza abruptamente, sin vale ni data, mientras que la dirigida a Cano incluye ambos.

Al editar el texto hemos intervenido para favorecer la lectura. En primer lugar, hemos establecido una separación de párrafos según criterios actuales. Hemos desarrollado todas las abreviaturas y, cuando se ha considerado necesario, hemos enmendado el texto, dejando siempre testimonio de ello en el aparato crítico. Hemos respetado las grafías de la época, salvo en el uso de $\mathrm{u} / \mathrm{v}$, que hemos regularizado para reflejar, respectivamente, los usos vocálico y consonántico. Se ha actualizado la puntuación y el uso de mayúsculas según el uso autorizado en la ediciones latinas modernas.

\section{h. Edición y traducción}

Genesius Sepulveda magistro N. ${ }^{60}$ Leoni S. D.

1. Multo facilius esse aliena scripta repraehendere quam aliquid scribere quod iusta repraehensione careat, nihil mirum est. Nam de operibus artificum iudicare posse et expertes eius artificii, qui operibus illis utuntur, testis est Aristoteles tertio de republica libro et item Apelles nobilis pictor, qui non gravate suam picturam ex iudicio sutoris emendavit, quamquam idem ferendum non putabat ut sutor extra calceos $^{61}$ iudicaret ${ }^{62}$. Quae cum mihi nota essent, sic fui ${ }^{63}$ semper animatus ut in meis opusculis, si quid esset erratum, facile paterer non solum ab eruditis tuique similibus, sed etiam a parum doctis emendari. Sed maxime vellem, id quod gravis probique viri officium esse duco, ut qui sibi iudicium de scriptis alterius sumit, ne inique agat, neve in libro alieno velit esse ambitiose ingeniosus et perperam in autoris iniuriam ingenium ostentare, neve incognita pro cognitis habeat et temere in alterius invidiam asserat. Quod qui faciunt, ii nonnumquam, dum aliorum inscitiam insectantur, suam produnt.

2. Non igitur mihi grave fuit, doctissime Leo, quod in libris Aristotelis de republica a me in latinum sermonem conversis et enarratis aliqua loca, in quibus offendisse tibi viderer, annotares, sed in eo tuam vel aequitatem vel gravitatem vel officium desideravi, quod rebus parum perspectis, temere de amici et hominis, ut ipse asseris, in studiis literarum non obscure versati diligentia et ingenio temere iudicares, tuoque errore pro re certa iactando scriptis meis obtrectares. Ego enim ut me nusquam in eis libris vel convertendis vel enarrandis lapsum fuisse nec puto nec assero, sic in locis a te notatis iniustam fuisse tuam repraehensionem certum habeo. Quod etsi commodius poterat coram explicari, tentabo tamen scripto quam brevissime potero proponendis locis et explicandis declarare.

\footnotetext{
60 magistro N. additum postea videtur.

61 calceos correximus : caltros $m s$.

62 Val. Max. 8,12,3; Plin. nat. 35,36,85. Sepúlveda, ep. 52, 4; 129,6.

63 Fuit $a$. corr.
} 
3. Ex libri tertii capite xii

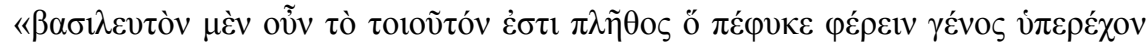

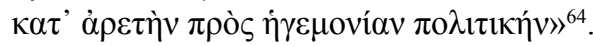

«Haec igitur multitudo regno est accommodata quae natura est habilis, ut ferat genus virtute praestans ad civilem principatum ${ }^{65}$.

Duplex est imperium, civile, quo regium quoque continetur ${ }^{66}$ et ad subiectorum utilitatem accommodatur, et herile, quod in servos habetur, et est, si in liberos exerceatur, tyrannicum. Talis igitur multitudo principem unum aut familiam virtute praestantem ferre potest, ut sibi civiliter imperet, non ut heriliter dominetur. Atque eodem modo accipiendum est civile imperium in multitudine aristocratica. Hoc est enim quod utraque multitudo ferre potest, ut sibi civiliter imperetur, non heriliter, illa in uno optimo principe, haec in aliquibus viris virtute praestantes. Illa igitur oratio ad verbum translata, «quae natura est ferre multitudinem gubernari valens liberorum imperio a virtute praestantibus ad imperium civile» sic est explicanda: «quae natura est apta ut ferat imperantem multitudinem, id est, possit imperio liberorum a virtute praestantibus gubernari ${ }^{67}$, idque prout ratio postulat imperii civilis.

4. Porro quod ipse pro civili imperio, quo rex fungitur, urbanos magistratus interpretaris, quam probe conveniat cum Aristotelis sensu viderint doctiores. Quis enim magistratus urbanos gerere ad regem pertinere putet, ut taceam quod qui recte et latine loquuntur numquam «urbanum magistratum» dicunt pro «civile imperante», sed ad differentiam referunt «municipalium vel agrestium magistratuum» ${ }^{68}$, de quibus Aristoteles in libro huius operis septimo et aliis in locis mentionem facit? ${ }^{69}$

5. Itaque quod de virtute boni civis et boni viri ais verum est, si ad rectam rempublicam referas, sed nihil pro te facit; quin potius declarat post illud «virum virtute praestantem» nihil opus esse addere «qua possit civiliter imperare». Nam quem virtute praestantem aut excellentem dicimus, huic haud dubie praestantem virtutem, quae imperantibus convenit, tribuimus, praesertim cum de imperiis rebusque publicis sermo est, sed quia vir talis potest et civiliter et heriliter imperare,

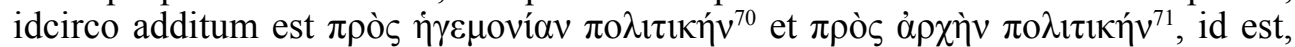
ut ipsis civiliter ${ }^{72}$ imperet $^{73}$. Nam quae multitudo natura vel moribus est apta cui heriliter imperetur, quales esse nonnullas testatur Aristoteles in primo et septimo libro, ea nec regno est apta nec optimatum administrationi, sed dominatui, cum

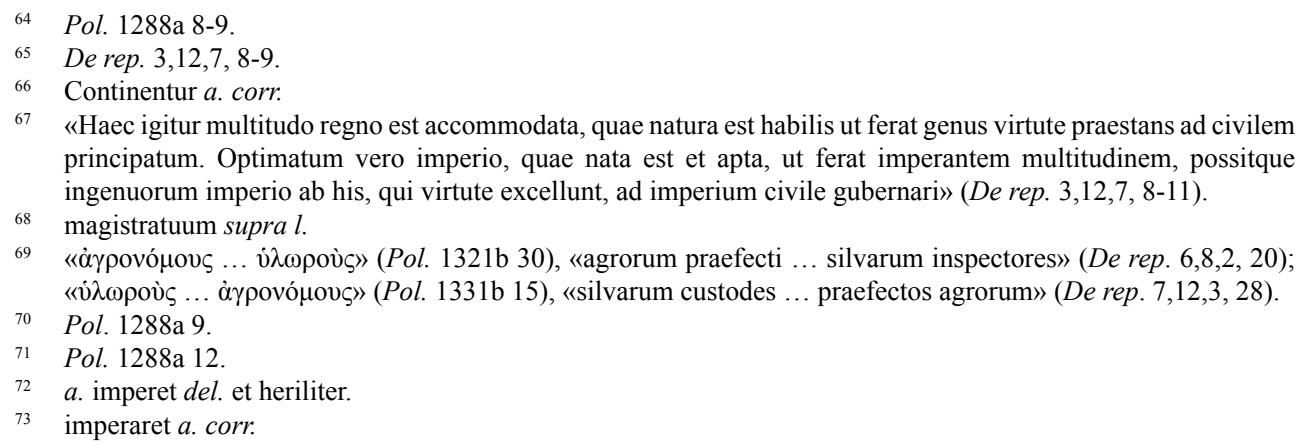


tales quasi servi sint gubernandi, illi vero utrique ut liberi, quod in aristocratica multitudine explicavit Aristoteles. Sed quia illud de virtute ${ }^{74}$ simpliciter loqueris, non recta est assertio tua. Nam in tyrannide paucorumque potentia et republica populari longe alia virtus est boni civis quam boni viri, eodem Aristotele auctore, nec illud rectius, quod imperium civile idem esse ais quod virtutem ad civiliter imperandum

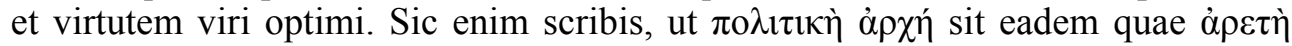

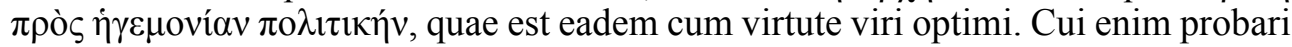
possit imperium idem esse quod virtutem, qua recte imperatur? Nec sensus igitur nec

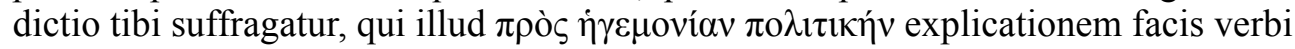

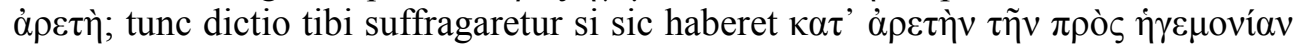

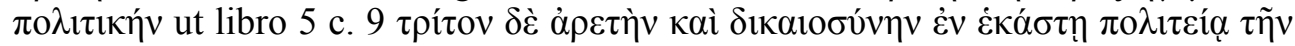
$\pi \rho \grave{\varsigma} \tau \tau \tilde{\eta} v \pi \mathrm{o} \lambda \imath \tau \varepsilon \dot{\alpha} \alpha v^{75}$.

6. Quod vero ais finem esse clausulae, quod ego principium ${ }^{76}$ putaverim, aequius erat puncti praepostere, ut pleraque alia, vitio librariorum collocati horum culpae assignare, quam levissima ne dicam puerili coniectura ductum meam intelligentiam condemnare.

\section{Ex eodem capite}

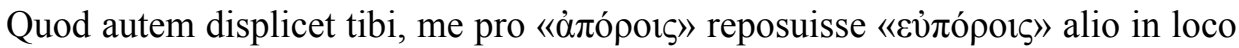

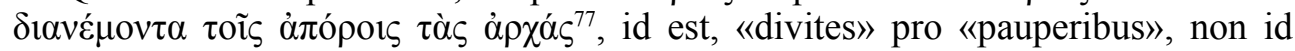
temere feci, nec sine fide veteris exemplaris quod secutus est vetus interpres nec sine magna ratione. Nam quod ais ${ }^{78}$ et in quo te insolentius iactas, in republica communi vocabulo dicta imperium esse penes pauperes, plane commentitium est, nam locupletum et egenorum mistionem esse rempublicam appellandam et esse temperaturam quamdam ex paucorum potentia et statu populari, licet magis inclinet ad popularem, Aristoteles ipse testatur lib. 4, cap. $8^{79}$.

8. In republica igitur lex divitibus magistratus distribuit pro dignitate, id est, non tam ex divitiis, ut in paucorum potentia, quam ex virtute quae vera dignitas est, idque pauperum suffragio. Nam in suffragiis ferendis mandandisque magistratibus et corrigendis bona respublica pauperibus communicatur, multo magis quam ut ipsi gerant magistratus. Nam ut Aristoteles ipse docet huius operis libro tertio, cap. 7, pauperibus summi magistratus non tuto commituntur, «quoniam (inquit) iniustitia et imprudentia facile modo in iniuriam, modo in errorem impellerentur, quamquam nihil eis tribuere, in bona scilicet republica nihil communicare res est plena periculi, quoniam si multi et egeni honorum expertes sint, urbem hostibus esse plenam necesse est. Superest igitur ut consultationes eis ac iudicia communicentur. Quocirca Solon et quidam alii legum latores huiusmodi civibus magistratus diligendi

illud de virtute supra $l$.

5 Pol. 1309a 36-37. «Tum virtus et iustitia in Republica cuiusque Reipublicae rationi accomodata» (De rep.

$5,9,1,3-4)$.

76 principio $a$. corr.

77 Pol. 1288a 14-15.

78 ais supra $l$.

79 Pol. 1293b, 33-34. 
et corrigendi facultatem tribuunt, ut autem separatim per se magistratus gerant, non permittunt» ${ }^{80}$.

9. Haec Aristoteles, quibus plane docet in republica ex divitibus et pauperibus temperata, divitibus potissimum, quibus et otium et virtus suppetit mandandos esse magistratus, sed suffragio pauperum, a quibus sint etiam corrigendi. Quod igitur Aristotelem plus millies tradere scribis, imperium in republica penes pauperes esse, id ne semel quidem ipsum dixisse certum habeo, ut praeceps tuum iudicium et inconsultam assertionem agnoscas, sed tu fortasse cum «multitudinem» dicit «pauperum turbam» interpretaris nec animadvertis in «multitudinis» nomine «populum» intelligi, qui ex divitibus et egenis constat, ut cum ait lib. 3, c. 5: «Cum vero multitudo imperium ad bonum publicum dirigens rem communem administrat, communi omnium vocabulo respublica dicitur» ${ }^{81}$. Quo in loco «multitudinem» appellari universum populum, qui divitibus et egenis constat, declarant verba ipsius, quae supra citavimus ex lib. 4 c. 8 . Itaque in republica communiter dicta imperium tradere penes pauperes esse, nihil aliud est quam rempublicam appellatam facere statum populare, qui hoc ipso definitur lib. 4 c. 4 , quod in eo pauperum multitudo imperium teneat, qui error hominis est miserabiliter in doctrina politica caecucientis.

\section{Ex eodem c. XII libri tertii}

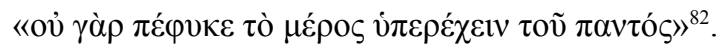

«Natura, quae partem toti praeferri non sinit, repugnante» ${ }^{83}$.

Haec ratio est eius quod proxime dixerat, non decere ut vir omni civitate superior virtute nunc imperet, nunc imperio pareat. Est igitur sensus: non decet statuere ut hic modo imperet, modo pareat alterius imperio, nam hoc esset partem praeferri seu praestare toti, quod natura non patitur. Nam quicumque ex civitate huic, ut caeteris praeferretur, et imperaret, esset tamquam pars huius, quoniam huius virtus omnium caeterorum civium virtutes complectitur et superat, ut cuiusque civis virtus huic comparata pars minima eius esse videatur. Itaque non ${ }^{84}$ ego virtutem eius, qui sit imperii socius, cum huius virtute comparo, ut ipse putasti, sed eius qui vicissim huic imperaret, ut caeteris privatis.

11. Nec tamen eo inficias locum esse ancipitem et cui possit tuus quoque sensus convenire, ut civitas totum, vir autem virtute tantopere praestans pars vocari intelligatur. Sed cum meus nihilo secius accommodetur et proximis verbis convenientius, non ideo debebas, cum quod minus tibi placeret, improbare, auctore Hieronymo, qui

80 «Nam licet his summi magistratus non recte committantur, quoniam iniustitia et imprudentia facile modo in iniuriam, modo in errorem impellerentur, tamen nihil eis tribuere, nihil communicare, res est plena periculi, quoniam si multi et egeni honorum expertes sint, urbem hostibus esse plenam necesse est. Superest igitur, ut consultationes eis ac iudicia communicentur. Quocirca Solon et quidam alii legumlatores huiusmodi civibus magistratus deligendi et corrigendi facultatem tribuunt, ut autem separatim per se magistratum gerant, non permittunt» (De rep. 3,7,3,17-24).

81 «Cum vero multitudo imperium ad bonum publicum dirigens rem communem administrat, communi omnium vocabulo Respublica dicitur» (De rep. 3,5,2,13-14).

82 Pol. 1288a 26-27.

${ }^{83}$ De rep. 3,12,8, 24-25.

84 non supral. 
sic iniquae Ruffini repraehensioni respondet. Ambiguitas «diversae interpretationi materiam praebet, dum unusquisque inter dubia quod sibi consequentius videtur, hoc transfert. Revolve», inquit, "Aristotelem et Alexandrum, Aristotelis volumina disserentem et quanta ambiguorum sit copia, eorum relectione cognosces, ut tandem desinas amicum tuum in eo repraehendere, quod ne per somnium quidem aliquando didicisti» ${ }^{85}$. Hactenus Hieronymus in Apologia ad Pammachium.

\section{Ex libri quarti capite secundo}

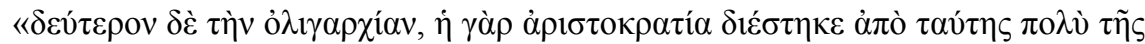
$\left.\pi \mathrm{o} \lambda \tau \tau \varepsilon i \alpha^{\prime}\right\rangle^{86}$.

«Proxime ab hac paucorum dominatum, quippe a quo longissime optimatum administratio abest» ${ }^{87}$.

Proximum, inquit, tyrannidi pravitatis locum tenet paucorum potentia, quoniam huic, id est paucorum potentiae, opposita est optimatum respublica: hoc est enim quod ait, has inter $\mathrm{se}^{88}$ multum distare. Est igitur sensus: ut tyrannis est omnium pessima respublica, quum opponitur regno, optimae reipublicae, sic paucorum potentia secundo loco prava est, quoniam statui optimatum, qui proximam regno, ut saepe dictum est, dignitatem tenet, opponitur. Respublica igitur optimatum tantum abest ut a regno plurimum distet, quemadmodum ipse vis intellegi, ut sit ei maxime coniuncta ${ }^{89}$ et cognata, ut hoc eodem capite docet Aristoteles his verbis: «De optimo statu reipublicae disserere, nihil est aliud quam de regno et optimatum administratione disputare, quoniam utraque respublica debet secundum virtutem copia rerum necessariarum et commodarum instructam constitui $»^{90}$, et libro 5 capite X: «Regnum», inquit, «ordinem optimatum aemulatur $\rangle^{91}$. Quod cum ita sit, quid tibi in mentem venit Aristotelis verba sic interpraetari, ut optimatum rempublicam a regno multum distare declarares, quod est optimas respublicas contrarias inter $\mathrm{se}^{92}$ facere? Ut enim quae locis maxime absunt haec inter $\mathrm{se}^{93}$ locis opposita sunt, sic specie contraria, quae specie plurimum distant (Meteor. 2$)^{94}$.

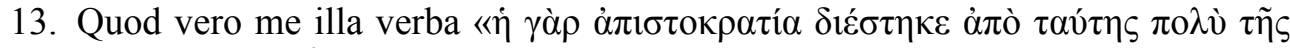
$\pi \mathrm{o} \lambda \iota \tau \varepsilon i ́ \alpha)^{\prime}$ retulisse $^{95}$ ad oppositionem paucorum potentiae et reipublicae optimatum negas ${ }^{96}$, quis non miretur tam caecam reprehendendi libidinem, cum id ita faciam, tum in convertendis eisdem verbis, tum in scholiis, ut apertius referre ${ }^{97}$ nequiverim?

\footnotetext{
85 «Quae res diversae interpretationi materiam praebuit: dum unusquisque inter dubia, quod sibi consequentius videtur, hoc transfert. Quid ad peregrina te mitto? Revolve Aristotelem et Alexandrum Aristotelis volumina disserentem et quanta ambiguorum sit copia, eorum lectione cognosces, ut tandem desinas amicum tuum in eo reprehendere, quod ne per somnium quidem aliquando didicisti» (Hier. Apologia adversus libros Rufini 1,20).

86 Pol. 1289b 3.

87 De rep. 4,2,2, 18-19.

88 interse $m s$.

89 coniuncta correximus : conuincta ms.

90 Pol. 1289a, 31. De rep. 4,2,1, 6-8.

1 Pol. 1310b, 31-32. De rep. 5,10,2, 1.

interse $m s$.

interse $m s$.

Meteor. 2 supra $l$.

a. retulisse del. non

negas supra l.

a. referre del. nequ
} 


\section{Ex libro 4 capite 4}

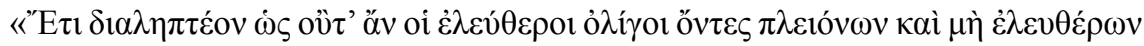
$\grave{\alpha} \rho \chi \omega \sigma \imath \delta \tilde{\eta} \mu \sigma \zeta\rangle^{98}$.

«Statuere oportet non protinus esse statum popularem, si liberi homines pauci in numero in plures et non liberos imperium teneant ${ }^{99}$.

Dixerat supra non satis esse ad paucorum potentiam nominandum, ut pauci teneant imperium, si pauperes hi sint; nec ad statum popularem, ut multi, si divites ${ }^{100}$, nam maius esse momentum in divitiis et paupertate quam in paucitate et multitudine, quarum illa divitibus, haec pauperibus accidit. Deinde subiicit, non tamen his rebus, id est divitiis et paupertate imperantium, definiendae sunt harum rerum publicarum formae, utrunque enim adesse oportet, hoc est, ut divites sint et pauci imperantes ad paucorum potentiam constituendam, pauperes autem et multi ad statum popularem; in quam sententiam sic libro 5 capite 9 scribit: «Duobus respublica popularis definiri videtur, tum eo quod summa potestas penes maiorem partem sit, tum libertate $\rangle^{101}$; quod ut hic apertius explicet, definitionem subiicit reipublicae popularis: «Status», inquit, «popularis est cum liberorum et pauperum qui plures numero $\operatorname{sint}^{102}$ arbitrio et voluntate geritur respublica» ${ }^{103}$.

15. Quod igitur contra omnem Philosophiae rationem esse dicis et falsum, negare statum popularem esse ubi pauci egeni imperium teneant, ipsa status popularis definitione redarguitur. Talis enim respublica nec status popularis est nec paucorum potentia, sed aliud genus, quod rarissime accidit, quamvis posset improprie ad alterutrum reduci. Itaque si pro $\delta \tilde{\eta} \mu \varsigma_{\text {in }}$ aliquo exemplari scriptum esset ỏ $\lambda ı \gamma \alpha \rho \chi i \alpha$ uterque sensus esset verus et dubitari posset uter esse $<t>$ commodior. Nunc, cum in omnibus exemplaribus $\delta \tilde{\eta} \mu \circ \varsigma$ legatur et hic sensus redargui nequeat, cur me accusas quod fidem omnium exemplarium sequi maluerim quam temere divinare et scripturam in vocem diversissimam invertere, idque praeter omnem rationem? Nam si utroque modo, ut dixi, in diversis exemplaribus legeretur, tamen ista quam tu probas scriptura esset ineptissima et importuna eiusdem sententiae in eodem capite repetitio. Nam hoc idem paulo ante dixerat illis verbis «si pauci essent egeni, tamen divitibus pluribus numero potentiores, nemo hanc paucorum potentiam nominaret» ${ }^{104}$.

16. Itaque, si scripturam ad istum modum mutare oportuit, nullo in loco minus erat mutanda, quam ubi ipse putasti. Habet enim sensum commodissimum. Nam supra dixerat hanc ${ }^{105}$ reipublicae ${ }^{106}$ formam non esse paucorum potentiam, nunc ne statum

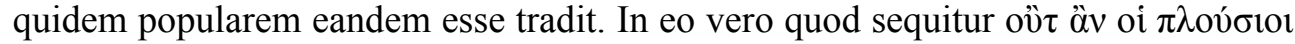

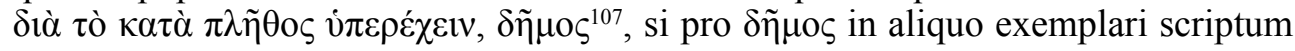

9 Pol. 1290b 9-11.

99 De rep. 4,4,2, 18-20.

100 p. diuites del. fuerint

101 Pol. 1310a 28-30. De rep. 5,9,5, 33-34.

102 sunt in $P$, f. 114 r.

103 Pol. 1290b 17-19. De rep. 4,4,2, 26-27.

104 Pol. 1290a 37-39. De rep. 4,4,1, 7-8.

105 hanc supra $l$.

106 rep. a. corr. -i- additum postea.

107 Pol. 1290b 14 
esset ỏ $\lambda$ ı $\alpha \rho \chi i ́ \alpha$ fortassis haec lectio commodior esse videretur ne bis idem eodem capite diceret, quoniam idem est sensus illorum verborum, «Si essent omnes mille trecenti ${ }^{108}$, etc. Utroque tamen modo verus esset sensus, ut repraehendi non debeam, quod scripturam non mutaverim praeter omnium exemplarium fidem. Meus enim quem secutus sum codex ab Aldo ${ }^{109}$ excusus cum quattuor manu scriptis vetustissimis Romae collatus fuit et emendatus; quae omnia exemplaria et quod secutus est vetus interpres hoc in loco consentiunt. Quae igitur falsa, pugnantia et ab omni Philosophiae ratione abhorrentia esse dicis, haec verissima et rectissime cohaerentia sunt et maxime cum Philosophiae ratione conveniunt.

17. Postremo, quod democratia hoc in loco Aristoteli vocari dicis non depravatam illam rempublicam quae solet hoc nomine nuncupari, sed omne genus reipublicae ubi penes populum est imperii summa, Aristotelis verba in eum sensum interpretaris qui ab ipso initio eiusdem capitis fuerat damnatus illis verbis «Neque vero debet, ut a quibusdam solet, democratia ${ }^{110}$ simpliciter statui, ubi summa potestas est penes multitudinem $\rangle^{111}$.

\section{De verbo $\delta \eta \mu \alpha \gamma \omega \gamma o ́ s$.}

«"Populares», inquis ${ }^{112}$, «homines" Cicero solet nominare qui populo placere student, non "duces populares"». Et nos scilicet ignorabamus et in eo sumus imprudentia lapsi quod pueris est notissimum. Quoniam igitur puerilia quoque me docere vis, ego vicissim, ut tibi gratiam cumulate referam, te Philosophi consuetudinem et sensum docebo. Populares homines latine, ut nosti, multifariam dicunt, nam qui sunt eiusdem populi, hi alter alterius «populares» nominantur. Item gregarii et vulgares privatique homines «populares» appellantur. Atque si quis quacumque ratione populo studeat eiusque auram aucupetur, hic quoque «popularis» dicitur, de quo genere hominum sic Cicero scribit in oratione pro Sextio, «qui ea quae faciebant quaeque dicebant multitudini iocunda esse volebant populares habebantur» ${ }^{113}$, et pro Cluentio de L. Quintio memorans «homo», inquit, «maxime popularis, qui omnes rumorum et concionum ventos colligere consuesceret» ${ }^{114}$;

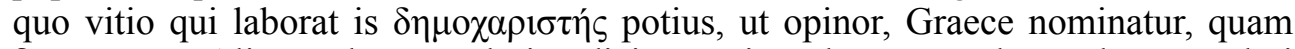
$\delta \eta \mu \alpha \gamma \omega \gamma$ ós. Alio modo «popularis» dicitur, qui se ducem praebet turbae populari ad divitum et optimatum potentiam et auctoritatem opugnandam et minuendam, et tales proprie dicuntur $\delta \eta \mu \alpha \gamma \omega \gamma o i$, qui omnia et dicunt et faciunt in optimatum seu divitum invidiam et quo plebi blandiantur, ut eius favore et viribus potentiores fiant, qua ratione multos sibi iam ad tyrannidem munivisse ipse testatur libro 5 capite 10 his verbis: «Nam tyranni plerique ex ducibus popularibus facti sunt, qui nobiles calumniando, ut sibi a populo fides haberetur, assecuti sunt ${ }^{115}$, atque hoc modo Panaetium apud Leontinos, Cypselum Corinthi, Pisistratum Athenis, Dionysium

\footnotetext{
8 De rep. $4,4,1,4$.

abaldo $m s$.

status popularis in Sepúlveda (1548: f. 113r).

Pol. 1290a 30. De rep. 4,4,1, 1-2.

inquis coniecimus : inquit $m s$.

Cic. Sest. 96.

Cic. Clu. 77.

Pol. 1310b15. De rep. 5,10,1, 13-15. Sunt assecuti in Sepúlveda (1548: f. 170r).
} 
Syracusis ex ducibus et assentatoribus popularibus tyrannos factos fuisse paulo post prodit. De quo genere hominum sic scribit libro quinto c. 6: uno modo, inquit, respublica paucorum mutatur, «si iniuriam inferant in multitudinem, quivis enim ad ducendum ${ }^{116}$ populum est idoneus, praesertim si quis ex ipsis paucis imperantibus sese ducem praebeat, ut Lygdamis in Naxo, qui huius insulae postea tyrannidem occupavit» ${ }^{117}$, et c. 8 ipsos $\delta \eta \mu \alpha \gamma \omega \gamma o v ̀$ maximos seu potentissimos esse dicit in republica populari ${ }^{118}$. Tales igitur homines qui non solum populo blandiuntur, sed etiam ei se duces praebent adversus nobilitatem proprie $\delta \eta \mu \alpha \gamma \omega \gamma o$, cum ab aliis auctoribus tum maxime ab Aristotele in hoc opere de republica passim nominantur attestante ipsa quoque verbi etymologia.

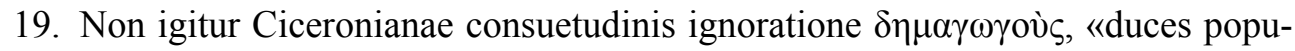
lares» converti, et interdum «adulatores populares», sed ut proprietatem vocabuli non minus latine simulque Aristotelis ${ }^{119}$ germanum sensum exprimerem, et item ut

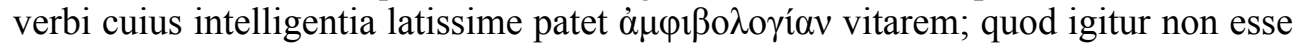
ferendum scripsisti, quantum sit tolerabilius quam ut temere ${ }^{120}$ quae parum percipis repraehendas, ipse videris ${ }^{121}$.

20. Caeterum non miror haec et supramemorata tibi parum fuisse animadversa, docto quidem et diligenti homini, sed diversis studiis occupatissimo. Erat tamen modestiae atque officii tui vel accuratius rem tractare, ut non prius de alienis scriptis iudicium ferres et in vulgus iactares quam omnia diligentissime perpendisses ${ }^{122}$, vel tuum negotium agere nec esse curiosum in alieno, ne in ea civitate cuius moribus et institutis perdiscendis forsitan quantum oportuit vacare nequivisti, ius nobis non tam legibus quam tuo arbitratu dicere velle, aut etiam Hippodamum agere cum alterius iniuria videreris. Quanquam aequius fortasse fuerit ridere et hilarius ${ }^{123}$ tui animi ingenuitatem amplecti, quam tibi succensere, qui te non ignorasse quid officii ratio postularet ingenue fateris, sed propter splendorem (sic enim scribis) mei nominis, haec te ambitiose fuisse conatum scilicet ut mecum certares, quod tibi magnae gloriae futurum esse existimare in ipso epistolae exordio profiteris.

\section{Ginés de Sepúlveda saluda al maestro León}

1. No hay que asombrarse de que sea mucho más fácil criticar los escritos ajenos que escribir algo que no pueda criticarse justamente. Pues Aristóteles, en el libro tercero de la Política, es testigo de que pueden opinar de las obras de los artesanos incluso los que se aprovechan de ellas sin poseer esa destreza, y también el distinguido pintor Apeles, que corrigió de buena gana su propia pintura por la opinión de un zapatero, aunque él mismo considerara que no había que aceptar que un zapatero

\footnotetext{
116 adducendum $a$. corr.

117 Pol. 1305a 37. De rep. 5,6,1, 2-5.

118 Pol. 1308a 23.

119 Aristoteles a. corr.

120 a. temere del. ipse tu

121 videris scripsimus : vederis ms.

122 perpendisses coniecimus : propedisses $m s$.

123 Hilarius $m s$.
} 
opinara sobre algo que no fueran los zapatos. Sabedor de ello, siempre he procurado aceptar de buen grado las correcciones a mis obras, no solo de los eruditos y émulos tuyos sino también de los poco versados, si es que había en ellas algún error. Pero querría, antes que nada, lo que considero el deber de un hombre serio y honesto, que quien emite juicios sobre las obras de otro no sea injusto ni quiera ser ocurrente con un libro ajeno por afán de protagonismo, ni alardee falsamente de talento para perjudicar al autor, ni dé por sabido lo que ignora, ni provoque irreflexivamente el desprestigio de otro. Quienes actúan así, al fustigar la ignorancia de los otros, ponen en evidencia la suya propia.

2. No me molestó, por tanto, doctísimo León, que en los libros de Aristóteles sobre la Política, que yo he traducido al latín y comentado, anotaras algunos pasajes en los que te parecía que había incurrido en error, sino que he echado en falta en ello tu equidad, seriedad y cortesía, porque, sin haber estudiado a fondo el asunto, opinaras sin fundamento sobre la minuciosidad y el talento de un amigo y de un hombre, como tú mismo afirmas, no escasamente versado en los estudios literarios y desacreditaras mis escritos jactándote de tu error como de cosa cierta. Como no creo ni sostengo haber estado siempre libre de error en la traducción o el comentario de estos libros, del mismo modo tengo la seguridad de que ha sido injusta tu reprehensión en los pasajes que anotaste. Aunque podría haber sido más oportuno darte estas explicaciones cara a cara, intentaré, sin embargo, en un escrito lo más breve posible manifestarte mi propuesta y explicación de los pasajes.

\section{Del libro tercero capítulo 12}

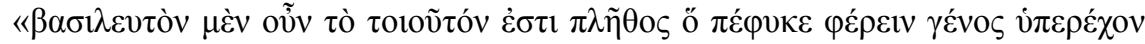

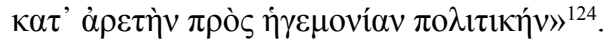

«Está dispuesto a la monarquía el pueblo aquel que de forma natural produce una raza que sobresale por su virtud en orden a la dirección política» ${ }^{125}$.

Existe un doble poder, el político, en el que se incluye también el que corresponde a los reyes y se acomoda a la utilidad de los súbditos; y el despótico, que se tiene para con los esclavos, y es tiránico si se ejerce con los ciudadanos libres. Tal pueblo, por tanto, puede aceptar que un príncipe o una familia que destaque por sus cualidades le mande políticamente, no que le domine despóticamente. Y del mismo modo ha de entenderse el poder político en la aristocracia. Pues esto es lo que uno y otro pueblos pueden aceptar, que se les mande como ciudadanos, no despóticamente, en el primer caso por un príncipe excelente, en el segundo por algunos hombres que destacan por sus cualidades. Estas son las palabras traducidas al pie de la letra: «la que por naturaleza es capaz de producir una población que sea gobernada, bajo mandato de hombres libres, por aquellos a quienes su aptitud capacita para el poder político», que hay que entender así: «la que por naturaleza es apta para producir una población

\footnotetext{
124 Es un pasaje dudoso. Newman, aunque lo defiende, lo considera sospechoso; Susemihl interpolado; para Dreizehnter conviven dos redacciones originales aristotélicas, pero ampliadas hasta hacerlas incomprensibles, vid. Aubonnet II,1: 207-208 y Bertelli-Moggi III: 257-258.

125 Como indicamos antes, la traducción castellana de los pasajes es la de García Gual - Pérez Jiménez (1986).
} 
que manda, o sea, que pueda ser gobernada bajo el imperio de los nobles por los que sobresalen en virtud», y esto según lo requiere la naturaleza del poder político.

4. Otros más doctos verán si se ajusta al sentido de Aristóteles tu interpretación del «poder político que desempeña el rey» como «magistrados de la ciudad» ${ }^{126}$. Pues, ¿quién puede considerar que son competencia del rey los magistrados de la ciudad, por no mencionar que los que se expresan en un latín correcto nunca hablan de urbanum magistratum para mencionar «al que ejerce el poder político», sino que se refieren por separado a los municipales vel agrestres magistratus, a los que hace mención Aristóteles en el libro VII de esta obra y en otros pasajes?

5. En efecto, es cierto lo que dices sobre la virtud del buen ciudadano y del hombre bueno, si te refieres a una forma recta de gobierno, pero no favorece tus argumentos; antes bien, pone de manifiesto que después de virum virtute praestantem no hace ninguna falta añadir qua possit civiliter imperare. Pues al que decimos que es praestantem o excellentem le atribuimos sin lugar a dudas la virtud destacada que conviene a los que mandan, especialmente si tratamos de poderes y asuntos públicos, pero dado que un hombre como ese puede mandar políticamente y despóticamente, por eso se ha añadido «para la dirección política» y «para el gobierno político», o sea, para que mande sobre ellos «políticamente». Pues el pueblo que es apto por naturaleza o costumbres para que se le mande despóticamente, como Aristóteles sostiene que hay algunos, en los libros primero y séptimo, no es apto ni para la monarquía ni para la aristocracia, sino para la oligarquía, ya que estos han de ser gobernados como esclavos y aquellos dos, en cambio, como libres, lo que explicó Aristóteles en la aristocracia. Pero como dices aquello de «la virtud sin más», no es exacto tu aserto. Pues en la tiranía, en la oligarquía y en la democracia es muy distinta la virtud del buen ciudadano de la del buen hombre, según el mismo Aristóteles. Y no es más exacto eso que dices, que el poder político sea el mismo que la virtud para mandar políticamente y la virtud de un hombre bueno. Pues escribes que «el gobierno de la polis» es lo mismo que «la virtud para la dirección de la polis», que es la misma que la «virtud de un hombre excelente». A decir verdad, ¿quién prodría aprobar que el poder es lo mismo que la virtud con la que se gobierna rectamente? Ni el sentido

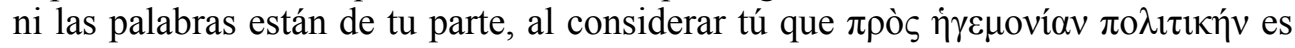

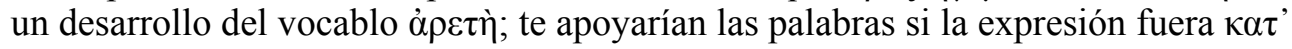

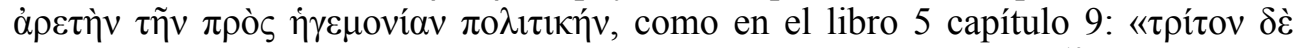

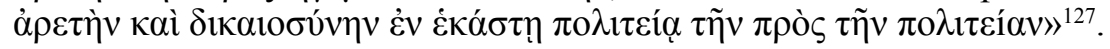

6. Con respecto a tu afirmación de que se trata del final de un período lo que yo más bien consideraría el principio ${ }^{128}$, habría sido más justo atribuir la culpa de esto a un punto colocado fuera de lugar, como otras muchas cosas, por error de los copistas, que condenar mi interpretación dejándote llevar de una conjetura futilísima, por no decir pueril.

\footnotetext{
126 Al no disponer del texto de León de Castro, no podemos matizar debidamente esta cuestión.

127 «Y, en tercer lugar, virtud y justicia, en cada régimen la adecuada a ese régimen».

128 El $\pi \rho \tilde{\tau} \tau o v$ del párrafo anterior, indica, efectivamente, que nos encontramos en el inicio de un periodo. Algunos editores (Ross, Aubonnet) lo señalan introduciendo un punto y aparte en el texto o en la traducción.
} 


\section{Del mismo capítulo}

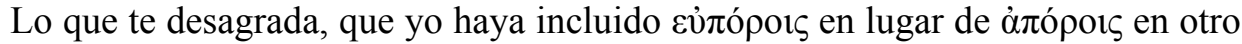

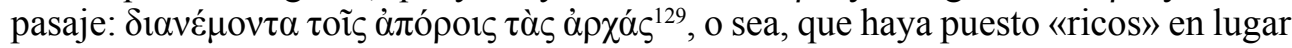
de «pobres», no lo he hecho a la ligera ni sin tener en cuenta la autoridad del viejo códice que siguió el viejo traductor ${ }^{130} \mathrm{y}$ con gran fundamento. Pues lo que sostienes y defiendes con tanta arrogancia, que en la llamada comúnmente «república» el poder pertenece a los pobres, es completamente falso, pues Aristóteles en el libro 4, capítulo 8 afirma que hay que llamar «república» a la unión de ricos y pobres y que es una mezcla de oligarquía y democracia, aunque se incline más por esta última ${ }^{131}$.

8. En la república, por tanto, la ley asigna las magistraturas a los ricos según su dignidad, es decir, no tanto por su riqueza, como en la oligarquía, sino por su virtud, que son los méritos auténticos, y ello con el voto de los pobres. Pues en las votaciones y elecciones y revocaciones de magistrados la república recta hace partícipes a los pobres, mucho más que ellos mismos desempeñen las magistraturas. Pues como enseña Aristóteles en el libro 3, capítulo 7 de esta obra, no se encomiendan por seguridad las magistraturas supremas a los pobres, «porque - dice- la injusticia y la imprudencia pueden convertirse fácilmente en afrenta o en error, aunque no concederles nada y no hacerles partícipes de nada es algo lleno de peligro en una república recta, porque si hubiese muchos necesitados privados de honores, por fuerza estaría la ciudad llena de enemigos. Queda, por tanto, hacerlos partícipes en las deliberaciones y en los tribunales. Por eso Solón y algunos otros legisladores atribuyen a los ciudadanos pobres la facultad de elegir y revocar magistrados, sin permitirles ejercer las magistraturas por ellos mismos autónomamente».

9. Estas son las palabras de Aristóteles, en las que muestra palmariamente que en la república surgida de la unión de ricos y pobres, se han de confiar las magistraturas especialmente a los ricos, que disponen de tiempo libre y virtud, pero con el voto de los pobres, por los cuales tendrían que ser también revocados. Por eso, lo que escribes que Aristóteles afirma más de mil veces, que el poder en la república está en los pobres, yo estoy seguro de que ni siquiera lo dijo una vez, para que reconozcas que tu opinión ha sido apresurada y tu afirmación irreflexiva, pero cuando él dice multitudo, tú quizá entiendes pauperum turba, y no te das cuenta de que cuando dice multitudo hay que entender populus, que está compuesto de ricos y pobres, como cuando dice en el libro 3 capítulo 5: «Y cuando la mayoría gobierna mirando por el bien común, recibe el nombre común a todos los regímenes políticos, república» ${ }^{132}$. En este pasaje las palabras del libro 4, capítulo 8, que antes cité, dejan claro que multitudo hace referencia a todo el pueblo, que consta de ricos y pobres. Así pues, escribir que en la comúnmente llamada república el poder reside en los pobres es convertir a la república en una democracia, que se define precisamente por esto

\footnotetext{
129 «Distribuye las magistraturas entre los pobres».

130 Se refiere, claro está, a Guillermo de Moerbecke.

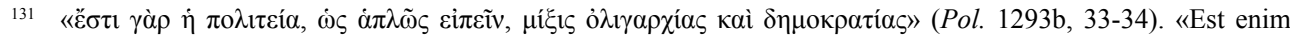
Respublica, ut simpliciter loquar, quaedam ex paucorum potentia et statu populari temperatura» (De rep. 4, 8,1, 11-12).

132 «Cum vero multitudo imperium ad bonum publicum dirigens rem communem administrat, communi omnium vocabulo Respublica dicitur» (De rep. 3,5,2,13-15).
} 
en el libro 4, capítulo 4, porque en él la masa de pobres tiene el poder, error que corresponde a un hombre lamentablemente cegato en teoría política ${ }^{133}$.

\section{Del mismo capítulo 12 del libro tercero}

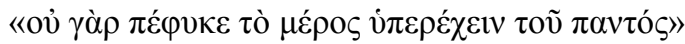

«La naturaleza no permite que la parte prime sobre el todo».

Esta es la razón de lo que Aristóteles había dicho poco antes, que no convenía que un hombre superior en virtud a toda la ciudad en ocasiones mande y en otras obedezca al poder. El sentido, por tanto, es este: no conviene establecer que este hombre unas veces mande y otras obedezca al poder de otro, pues esto sería que la parte sea preferida o supere al todo, lo que va contra la naturaleza. Pues cualquiera de la ciudad que fuera antepuesto y mandara a este, al igual que a los demás, sería como parte de este, porque la virtud de este engloba y supera las virtudes de todos los demás, de modo que la virtud de cualquier ciudadano comparada con la de este parezca que es una parte mínima de ella ${ }^{134}$. Así pues, no comparo la virtud de quien es su compañero en el ejercicio del poder con su virtud, como has creído, sino la de quien mandara sobre él igual que sobre los demás ciudadanos corrientes.

11. Y no niego, sin embargo, que sea un pasaje ambiguo al que pueda convenir también tu interpretación, de modo que se interprete que a la ciudad se le llame 'todo' y a un hombre tan insigne por su virtud se le llame sin embargo 'una parte'135, pero como mi interpretación no es menos apropiada y es más adecuada a las palabras cercanas, no debías en una situación así, aunque algo no te agradadase, censurarme, tal como sostiene Jerónimo, que responde así a la injusta crítica de Rufino: la ambigüedad «proporciona oportunidad para interpretaciones diferentes, al traducir cada uno en pasajes dudosos lo que le parece más consistente. Consulta - dice-a Aristóteles y a Alejandro, su comentarista, y con su relectura podrás apreciar qué gran cantidad de ambigüedades existe, y dejarás de reprender a tu amigo lo que ni siquiera se te ha ocurrido alguna vez en sueños». Hasta aquí Jerónimo en su Apología a Pamaquio.

133 Aunque este pasaje (Pol. 1288a 14-15) comparte, desde un punto de vista textual, los problemas del fragmento

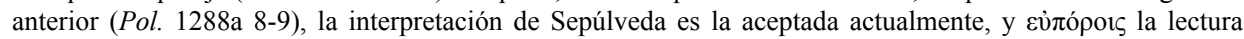
unánime de los editores modernos (Bekker, Susemihl, Susemihl \& Hicks, Immisch, Newman, Ross, Dreizehnter, Aubonnet y Accatino-Curnis) en este pasaje. Cf. Aubonnet II,1, p. 276, aunque la expresión $\kappa \alpha \tau$ ’ ’̇́íav es problemática.

134 Parece que la crítica recibida en este pasaje dio lugar posteriormente a uno de los escolios que Sepúlveda incorporó como novedad para la planificada segunda edición de sus De republica libri VIII, que nunca llegó a publicarse: «Aut sensus est, si vir tantus modo imperaret, modo pareret imperio, is esset unus de numero civium et pars civitatis. Atque ita fieret quod natura non patitur, ut pars totum excellat, cum hic unus virtute praestet omni civitati» add. mg. CMa (ad f. 107v,5), vid. Solana Pujalte - García Pinilla (2015: 1029).

$135 \mathrm{La}$ interpretación que suelen dar editores y comentaristas a este pasaje coincide con la de Sepúlveda. Cf. Aubonnet II,1, p. 277 «Tout qu'il constitue par raport à tous les autres ensemble, puisqu'il les surpasse en vertu». Susemihl-Hicks I, p. 445: «For it is not natural that the part should outweigh the whole, and the possessor of such extraordinary eminence has happened to be in this case» viz. that all the others together stand to him as part to whole. The ordinary interpretation is, «For it is not the course of nature that the part should surpass the whole, whereas this happens when a man is very superior to the rest». 


\section{Del libro cuarto, capítulo segundo}

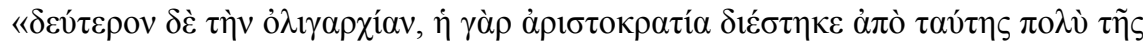
$\pi \mathrm{o} \lambda \imath \varepsilon \dot{\alpha} \alpha \varsigma »$.

«Y en segundo lugar la oligarquía (pues la aristocracia dista mucho de este régimen)».

Dice que el puesto más cercano a la tiranía, en lo que a desviación se refiere, corresponde a la oligarquía, porque a esta (es decir, a la oligarquía) se opone la aristocracia. En efecto, esto es lo que quiere decir que estas están muy apartadas entre sí. Por consiguiente, el sentido es este: así como la tiranía es la peor forma de gobierno de todas, pues se contrapone a la monarquía, que es la mejor de todas, así también la oligarquía es la segunda más desviada, porque se contrapone a la aristocracia, que ocupa el puesto siguiente a la monarquía en cuanto a dignidad, como se ha dicho a menudo. Por consiguiente, la aristocracia no solo no se aparta mucho de la monarquía, como tú quieres entender, sino que está estrechamente unida y relacionada con ella, tal como enseña Aristóteles en el mismo capítulo, con las siguientes palabras: «Hablar sobre la mejor forma de Estado no es otra cosa que disputar sobre estos nombres, ya que ambos deben constituirse según la virtud provista de abundancia de cosas necesarias y convenientes»; y en el libro 5, capítulo décimo, afirma: «La monarquía imita el orden de la aristocracia». Siendo esto así, ¿cómo se te vino a la cabeza interpretar las palabras de Aristóteles de tal modo que llegaras a afirmar que la aristocracia está muy apartada de la monarquía, afirmación que implica situar las mejores formas de gobierno una contra la otra? En efecto, así como las cosas que están más distantes en cuanto a la posición son opuestas entre sí en cuanto a la posición, de igual manera son opuestas en especie las cosas que se apartan mucho en especie (Meteor. 2).

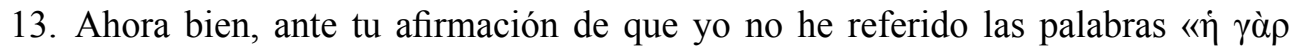

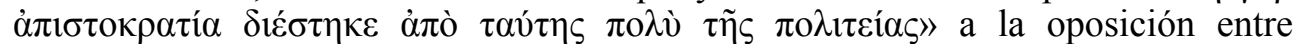
oligarquía y aristocracia, ¿quién dejará de asombrarse de que tu pasión por reprochar sea tan ciega, siendo así que tanto en la traducción misma de las palabras como en los escolios lo hago de tal modo que no podría haberlo referido más explícitamente? ${ }^{136}$

14. Del libro 4, capítulo 4

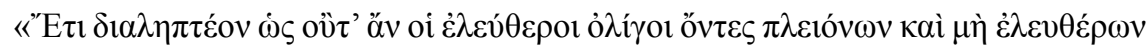
$\grave{\rho} \chi \omega \sigma \imath \delta \tilde{\eta} \mu \sigma \varsigma »$.

«Se ha de especificar además que ni aunque los libres, siendo pocos, manden sobre muchos y no libres, tendremos democracia».

136 Este es el texto: «Commemoratis brevi epilogo iis de quibus III libro disputatum fuit, deinceps disserendum esse ait de Republica communi vocabulo nuncupata, et de Rebuspublicis depravatis, ex quibus tyrannidem cunctarum pessimam esse dicit, propterea quod ab optima Republica hoc est a regno desciverit; proxime a tyrannide paucorum potentia in vitio esse, quia longissime distat ab optimatum Republica; Rempublicam vero popularem in malis medium tenere, id est, esse mediocriter et toleranter malam, quia est opposita Reipublicae communi vocabulo dictae, quae ultimum locum tenet inter rectas» (De rep., schol. 4,2,1, 1-10). 
Aristóteles había afirmado ${ }^{137}$ antes que para decir que existe una oligarquía no bastaba con que unos pocos se hagan con el mando, si estos eran pobres; y tampoco, para decir que exista una democracia, que sean muchos, si son ricos; pues es más relevante la riqueza y la pobreza que el número reducido o abundante: el primero de estos se da con los ricos, el segundo, con los pobres. A continuación añade que, sin embargo, estas formas de gobierno no deben definirse por estos hechos (es decir, la riqueza y pobreza de los que mandan), pues es preciso que haya una y otra cosa: esto es, para establecer una oligarquía, que los que mandan sean ricos y pocos; y para una democracia, que sean pobres y muchos. En este sentido, escribe así en el libro 5, capítulo 9: «la democracia parece definirse por dos cosas, tanto porque la suprema potestad esté en poder de la mayor parte, como por la libertad». Y para exponerlo en este lugar más claramente, añade la definición de democracia, diciendo: «hay democracia cuando el Estado se gobierna por el arbitrio y voluntad de los libres y de los pobres (que son más en número)».

15. Por consiguiente, tu afirmación de que es falso y contrario a toda razón filosófica decir que no hay democracia donde unos pocos pobres disponen del poder, se refuta con la definición misma de democracia. En efecto, tal gobierno no es ni democracia ni oligarquía, sino un tipo diferente, que muy rara vez se produce, aunque impropiamente podría reducirse a cualquiera de los dos. Así pues, si en algún manuscrito estuviera escrito ó $\lambda \imath \gamma \alpha \rho \chi i ́ \alpha$ en vez de $\delta \tilde{\eta} \mu \circ \varsigma$, tanto un sentido como el otro sería verdadero y podría dudarse cuál de ambos era más pertinente. Ahora bien, como en todos los manuscritos se lee $\delta \tilde{\eta} \mu$ o $\varsigma$ y este sentido no puede refutarse, ¿por qué me reprochas que haya preferido mantenerme fiel a la lectura de todos los manuscritos, antes que conjeturar a la ligera y modificar el texto en favor de una expresión totalmente diversa, y esto faltando a toda razón? En efecto, aunque en copias diversas el pasaje apareciera de uno y otro modo, como dije, con todo esa reiteración de la misma idea en el mismo capítulo, que a ti te parece bien, sería totalmente inapropiada e improcedente. Pues esto mismo lo había dicho poco antes con las palabras citadas «si los pobres fueran pocos, pero más potentes que los ricos mayores en número, ninguno lo llamaría oligarquía».

16. Por tanto, si era necesario cambiar de este modo el texto, ningún lugar era menos apto para cambiarlo que donde tú pensaste. En efecto, presenta un sentido plenamente adecuado; pues antes había afirmado que esta forma de gobierno no es una oligarquía, y ahora apunta que tampoco es una democracia. Por contra, si

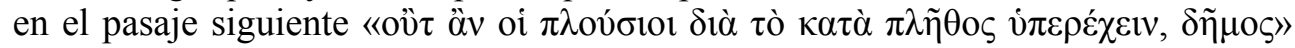

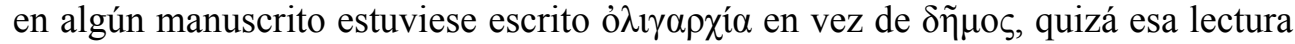
parecería más adecuada, para evitar decir lo mismo dos veces en el mismo capítulo (en efecto, es idéntico el sentido de las palabras «si fuesen todos mil trescientos», etc) ${ }^{138}$. Aun así, de uno y otro modo el sentido sería verdadero, de modo que no se me

137 Lo que desarrolla a continuación es un resumen de Pol. 1290a 41 - 1290b 20; De rep. 3, 4, 2, 10-24.

138 Tanto en Pol. 1290b 11 como en 1290b 15 la lectura de los mss. es siempre $\delta \tilde{\eta} \mu \circ \varsigma$, como señaló certeramente Sepúlveda. No obstante, las interpretaciones de los editores varían en ambos pasajes. En el primero, considerado corrupto por Johannes Camerarius (1581, p. 147), se ha aceptado unánimemente la lectura $\delta \tilde{\eta} \mu o \varsigma$, salvo Christian Garve (1799, p. 302) que postuló ỏ $\lambda \gamma \alpha \rho \chi i ́ \alpha$. En el segundo, los editores han aceptado mayoritariamente la lectura $\delta \tilde{\eta} \mu \mathrm{s}$ (Bekker [1837], Susemihl, Immisch, Dreizehnter, Aubonnet, Bertelli \& Moggi), pero Bojesen (1844) conjeturó ỏ $\lambda \imath \alpha \rho \chi i ́ \alpha$, para evitar la repetición a la que se hace referencia en el texto de Sepúlveda, y le 
debería reprochar no haber cambiado el texto sin el apoyo de ningún manuscrito. En efecto, el ejemplar de la edición aldina que he usado fue colacionado y corregido en Roma con cuatro manuscritos muy antiguos; y todos los manuscritos y el que usó el antiguo traductor coinciden en este lugar ${ }^{139}$. Por consiguiente, lo que afirmas que es falso, contradictorio e incompatible con toda razón filosófica, es totalmente cierto y coherente punto por punto y se adecua al máximo con la razón filosófica.

17. Por último, respecto a lo que afirmas de que para Aristóteles en este lugar se llama «democracia» no a aquella forma de gobierno degenerada que suele señalarse con este nombre, sino toda clase de gobierno en que el mando absoluto está en manos del pueblo, estás interpretando las palabras de Aristóteles en un sentido que él había condenado personalmente al comienzo del mismo capítulo con las palabras «pero no debe establecerse, como algunos suelen hacer, que hay democracia sin más donde la masa tiene la potestad suprema».

\section{En cuanto al término $\delta \eta \mu \alpha \gamma \omega \gamma o ́ s$.}

Dices: «Cicerón suele llamar populares homines a los que se esfuerzan por agradar al pueblo, no duces populares». Y yo, claro, no tenía ni idea y he caído por inadvertencia en algo que los niños se saben perfectamente. Bueno, ya que también me quieres enseñar niñerías, yo, por mi parte y para no quedarme atrás en agradecimiento, te enseñaré las expresiones habituales del Filósofo y su sentido. En latín, como sabes, se usa la expresión homines populares en muchos sentidos; pues los que son del mismo pueblo, estos se llaman entre sí populares; igualmente, a los hombres del montón y a los corrientes y a los don nadie se les dice populares; y si alguno quiere ganarse al pueblo por el medio que sea y anda a la caza de su favor, este también recibe el nombre de popularis, una clase de hombres de la que Cicerón en su discurso En defensa de Sestio escribe así: «eran tenidos por populares los que querían que fuera a gusto del populacho lo que hacían y lo que decían»; y en el En defensa de Cluencio, al hacer memoria de Lucio Quincio, dice: «hombre popular al máximo, que se había acostumbrado a recoger todo soplo de la opinión pública

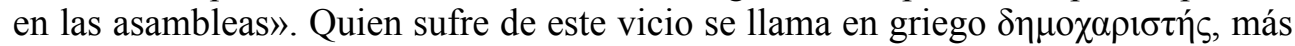
que $\delta \eta \mu \alpha \gamma \omega \gamma o ́ s$, a mi modo de ver. Popularis se le dice, de otro modo, al que se ofrece como caudillo de una turbamulta con el objetivo de atacar y reducir el poder y autoridad de los ricos y de los nobles; los tales se llaman propiamente $\delta \eta \mu \alpha \gamma \omega \gamma o$, que todo lo que dicen y hacen es por malquerencia hacia los nobles o los ricos y para halagar a la plebe, para hacerse más poderosos con su favor y sus fuerzas. Él mismo, en el libro 5, capítulo 10, da testimonio de que muchos han alcanzado la tiranía por este procedimiento: «Pues la mayoría de los tiranos se han creado a partir de demagogos, que calumniando a los nobles para ganarse la confianza del pueblo, la han conseguido», y expone poco después que Panecio en Leontino,

siguieron Welldon, Newmann (com. en 4, pp. 89 y 160-1) y Ross. Estas divergencias interpretativas tienen su razón de ser en que Aristóteles no siempre definió del mismo modo el rasgo distintivo de los sistemas políticos. En este pasaje y en 1279 b 39 ss. puso el énfasis en la riqueza y la pobreza, pero en 1291b 37 ss., 1310a 28ss. y 1317 b 4ss. en la mayoría numérica.

139 Remitimos a lo dicho en la sección d) de la introducción: Materiales usados en la composición de la carta. Sepúlveda, en coherencia con lo dicho en el texto de su carta, había introducido una anotación ms. a $1290 \mathrm{~b} 15$ en el ejemplar aldino de su propiedad, matizando: «ỏ $\lambda \imath \alpha \rho \chi i ́ \alpha$ forsitan legendum». 
Cípselo en Corinto, Pisístrato en Atenas y Dionisio en Siracusa pasaron de ser caudillos y aduladores populares a tiranos. Sobre esta clase de hombres escribe así en el libro quinto, capítulo 6: dice que la oligarquía se transforma de un solo modo, «si infligen un daño a la masa, pues cualquiera es idóneo para conducir al pueblo, especialmente si uno de los propios oligarcas se erige en jefe, como Ligdamis en Naxos, que después ocupó la tiranía en esta isla». Y en el capítulo 8 afirma que esos mismos «demagogos» son los más importantes o poderosos en la democracia. En consecuencia, los hombres capaces no solo de halagar al populacho, sino también de ofrecerse como caudillos contra la nobleza se llaman propiamente «demagogos», tanto por parte de otros autores como, especialmente, por parte de Aristóteles por todas partes en esta obra de la Política, con el apoyo, además, de la etimología de la palabra.

19. En consecuencia, no he traducido $\delta \eta \mu \alpha \gamma \omega \gamma o$ por duces populares y, a veces, adulatores populares por desconocimiento del uso ciceroniano, sino para expresar la propiedad del término en buena latinidad, y a la vez, el sentido literal de Aristóteles, y también para evitar la anfibología de una palabra que tiene muchísimas acepciones. Por consiguiente, en cuanto a lo que escribiste de que era inaceptable, tú verás en qué medida es más tolerable que lanzar reproches a la ligera sobre cosas que no entiendes bien.

20. Por lo demás, no me asombro de que en esto último y en lo antes tratado no te hayas fijado bien, tú que eres, ciertamente, un hombre instruido y minucioso, pero tan ocupado en afanes diversos. Ahora bien, correspondía a tu moderación y cortesía, o bien trabajar el asunto con más diligencia-de modo que no emitieras un juicio sobre los escritos de otros y lo divulgaras antes de haberlo sopesado con todo cuidado-, o bien dedicarte a tus asuntos y no ser quisquilloso en lo que no te corresponde, no vaya a ser que, en la ciudad en la que no pudiste quizá dedicarte todo lo que convenía para aprender sus usos y legislación, parezca que quieres administrar justicia sobre mí, no tanto en razón de las leyes como según tu capricho, o incluso que quieres dártelas de Hipódamo, con daño del prójimo ${ }^{140}$. A decir verdad, quizá sería más razonable reírse y acoger el candor de tu espíritu con mucho buen humor, más que irritarme contigo, pues reconoces noblemente no desconocer qué era lo que correspondía al deber, pero que por el brillo de mi prestigio (pues así escribes) acometiste esta tarea por deseo de gloria; a la vista está que para rivalizar conmigo, cosa que, como confiesas al comienzo mismo de tu carta, considerabas que te proporcionaría un gran prestigio ${ }^{141}$.

140 Hipódamo de Mileto es objeto de amplio comentario y crítica en la Política de Aristóteles, libro 2, capítulo 6. Además de diseñar la distribución urbana que lleva su nombre, proyectó las instituciones ciudadanas, punto este que suscita la severa crítica del Estagirita.

141 La última frase encierra el colmo de la ironía continuada de Sepúlveda, jugando con las palabras del propio León de Castro y con los sentidos de la palabra gloria: la traducción de arriba se apoya en el sentido de 'prestigio', 'reputación'; pero igualmente podría haberse optado por el sentido negativo de 'presunción', 'jactancia', 'fanfarronería', lo que proporciona el segundo sentido: intentar enfrentarse a Sepúlveda pone de evidencia el orgullo presuntuoso de León de Castro. 


\section{Referencias bibliográficas}

Alcalá Galve, Ángel (1991), Proceso inquisitorial de Fray Luis de León, Valladolid: Junta de Castilla y León.

Arango y Escandón, Alejandro (1856), Proceso del P. M. Fray Luis de León: ensayo histórico, México: Andrada y Escalante.

Aubonnet, Jean (1968), Aristote, Politique. Texte établi et traduit par J. Aubonnet, Paris: Belles Lettres, $2 \mathrm{v}$.

Bécares Botas, Vicente (2007), Librerias salmantinas del siglo XVI, [Burgos, Segovia]: Fundación Instituto Castellano y Leonés de la Lengua, Caja Segovia.

Bécares,Vicente, Iglesias, Alejandro Luis (1992), La librería de Benito Boyer. Medina del Campo, 1592, Salamanca: Junta de Castilla y León.

Bekker, Immanuel (1837), Aristotelis De Republica libri VIII et Oeconomica ex recensione Immanuelis Bekkeri. Accedunt Rerumpublicarum Reliquiae ex editione C. F. Newmann, Oxoniii: e Typographeo Academico.

Bertelli, Lucio, Moggi, Mauro (2011-), Aristotele, La politica. Direzione di Lucio Bertelli e Mauro Moggi. A cura di Michele Curnis, Giuliana Besso, Federica Pezzoli, Paolo Accattino, Barbara Guagliumi, Mirko Canevaro, Maria Elena de Luna, Cesare Zizza, Roma: L'Erma di Bretschneider, 2011-, 5 v.

Bojesen, Ernst Frederik (1844-45), Bidrag til Fortolkningen af Aristoteles's Bøger om Staten, Kjøbenhavn: J. C. Scharling.

Camerarius, Joachim (1581), Politicorum et Oeconomicorum Aristotelis Interpretationes et Explicationes accuratae ... autore Ioachimo Camerario, Francofurti: apud Andream Wechelum.

Coroleu, Alejandro (1996a), «Ioannes Genesius Sepulveda versus Franciscus Vatablus. A propósito de la fortuna de las traducciones latinas de Juan Ginés de Sepúlveda», Habis 27: 277-281.

Coroleu, Alejandro (1996b), «The Fortuna of Juan Ginés de Sepúlveda's Translations of Aristotle and of Alexander of Aphrodisias», JWI 59: 325-332.

Coroleu, Alejandro (2009), «Notas críticas (y casi contemporáneas) a la traducción de Juan Ginés de Sepúlveda de la Política aristotélica», Euphrosyne n. s. 37: 375-379.

Dávila Pérez, Antonio (2009), «"Regnavit a ligno Deus, affirmat Arias Montano, negat Lindanus": revisión de la polémica Arias Montano-Lindanus a la luz de los nuevos documentos», HumLov 58: 125-189.

Domínguez Domínguez, Juan Francisco (2013), «Correspondencia de Pedro Chacón (II): carta n. ${ }^{\circ}$ 3. Pedro Chacón a León de Castro», Ciudad de Dios 226: 203-244.

Domínguez Domínguez, Juan Francisco (2015), «Biblia y Humanismo: León de Castro y Juan del Caño», Helmantica 66: 203-253.

Domínguez Domínguez, Juan Francisco (ed.) (2012), Diccionario biográfico y bibliográfico del humanismo español (siglos XV-XVII), Madrid: Ediciones Clásicas.

Domínguez Reboiras, Francisco (1998), Gaspar de Grajal (1530-1575). Frühneuzeitliche Bibelwissenschaft im Streit mit Universität und Inquisition, Münster: Aschendorff.

Dreizehnter, Alois (1970), Aristoteles' Politik. Eingeleitet, kritisch herausgegeben und mit Indices versehen von A. Dreizehnter, München: Wilhelm Fink.

Fuente, Vicente de la (1880), Biografía de León de Castro, Madrid: Eusebio Aguado.

García García, Antonio, Cantelar Rodríguez, Francisco, Nieto Cumplido, Manuel (1976), Catálogo de manuscritos e incunables de la Catedral de Córdoba, Salamanca: Universidad Pontificia. 
García Gual, Carlos, Pérez Jiménez, Aurelio (1986), Aristóteles, Política. Traducción, prólogo y notas de C. García Gual y A. Pérez Jiménez, Madrid: Alianza.

García Pinilla, Ignacio J., Solana Pujalte, Julián (1996). «Correspondencia inédita entre Juan Ginés de Sepúlveda y Miguel de Arcos», Helmantica 47: 142-143.

Garve, Christian (1799), Die Politik des Aristoteles. Übers. von Christian Garve. Hrsg. u. mit Anm. u. Abh. von Georg Gustav Fülleborn, Breslau: W. G. Korn.

Green, Otis H. (1940), «A note on Spanish Humanism. Sepúlveda and his Traslation of Aristotle's Politics», Hispanic Review 8: 339-342.

Herrero de Jáuregui, Miguel, Arenas-Dolz, Francisco (2013), Juan Ginés de Sepúlveda, Obras completas XVI,1-2. Traducción latina de la «Política» de Aristóteles. Edición crítica y traducción de M. Herrero de Jáuregui y F. Arenas-Dolz, Pozoblanco: Ayuntamiento, 2 v. ( = De rep.).

Immisch, Otto (1909), Aristotelis Politica post Fr. Susemihlium recognovit O. Immisch, Lipsiae: in aedibus B. G. Teubneri.

Immisch, Otto (1929): Aristotelis Politica post Fr. Susemihlium recognovit O. Immisch. Editio altera correctior, Lipsiae: in aedibus B. G. Teubneri.

López Rueda, José (1973), Helenistas españoles del siglo XVI, Madrid: CSIC.

Losada, Ángel (1949), Juan Ginés de Sepúlveda a través de de su «Epistolario» y nuevos documentos, Madrid: CSIC. Reimpr. de 1973.

Madroñal Durán, Abraham (2002), «Los Refranes o Proverbios en Romance (1555), de Hernán Núñez, Pinciano», Revista de literatura 64: 5-39.

Menéndez Pelayo, Marcelino (1992), Historia de los heterodoxos españoles, Madrid: CSIC, 1992 (Reprod. facs. de la ed. de Madrid : C.S.I.C., 1947), 2 v.

Moreno Gallego, Valentín (1997), «Perfiles universitarios y exegéticos de León de Castro», en A. Mestre Sanchís, E. Giménez López, Disidencias y exilios en la España moderna, Alicante: Universidad: 55-70.

Moreno Gallego, Valentín, Solana Pujalte, Julián, García Pinilla, Ignacio J. (2001), «Dos memoriales de Juan Ginés de Sepúlveda a Felipe II y otra documentación inédita», BRAH 198, 1: 131-154.

Muñoz Machado, Santiago (2012), Biografía de Juan Ginés de Sepúlveda. Obras Completas, vol. XVII, Pozoblanco: Ayuntamiento.

Newman, William L. (1887-1902), The Politics of Aristotle with an Introduction, two prefatory essays and notes critical and explanatory by W. L. Newman, Oxford: Clarendon Press, 4 v.

Nieto Cumplido, Manuel (1979) «Fondos librarios de Juan Ginés de Sepúlveda en la Biblioteca de la Catedral de Córdoba», Studia Albornotiana 37: 745-750.

Pinta Llorente, Manuel de la (1935), Procesos Inquisitoriales contra los Catedráticos Hebraistas de Salamanca: Gaspar de Grajal, Martín de Cantalapriedra y Fray Luis de León, vol. I, Madrid: Monasterio de El Escorial.

Rojo Vega, Anastasio (1997), «El maestro León de Castro (1585): la Biblioteca de un Humanista», Perficit 21: 55-88.

Ross, William D. $\left(1967^{4}\right)$ Aristotelis Politica. Recognovit brevique adnotatione critica instruxit W. D. Ross, Oxonii: e Typographeo Clarendoniano.

Ruiz Fidalgo, Lorenzo (1994), La imprenta en Salamanca (1501-1600), Madrid: Arco libros, $3 \mathrm{v}$.

San José Lera, Javier (2012), «Libros y lectura en los procesos inquisitoriales de los profesores salmanticenses del siglo XVI», en M. J. Vega Ramos, I. Nakládalová (coords.), Lectura y culpa en el siglo XVI / Reading and guilt in the 16th century, Barcelona: Universitat Autònoma de Barcelona:. 63-92. 
Sepúlveda, Juan Ginés de (1548), Aristotelis de Republica libri VIII. Interprete et enarratore Io. Genesio Sepulueda Cordubensi. Ad Philippum Hispaniarum Principem. Parisiis: apud Vascosanum, uia Iacobea, ad insigne Fontis.

Sepúlveda, Juan Ginés de (2007), Obras Completas, VIII, Epistolario. Edición crítica, traducción e introducción filológica I. J. García Pinilla y J. Solana Pujalte. Introducción histórica de J. Gil, Pozoblanco: Ayuntamiento.

Signes Codoñer, Juan, (2001) «"Es de la Universidad de Salamanca”. La biblioteca del Pinciano, su formación y su donación a la Universidad de Salamanca», en J. Signes Codoñer, C. Codoñer Merino, A. Domingo Malvadi, Biblioteca y epistolario de Hernán Núñez de Guzmán (El Pinciano). Una aproximación al humanismo español del siglo XVI, Madrid: CSIC: 1-144.

Solana Pujalte, Julián (2000), «Los Errata Petri Alcyonii in interpretatione libri Aristotelis de incessu animalium de Juan Ginés de Sepúlveda: ¿obra quemada, no impresa o no publicada?», Acta Conventus Neo-Latini Abulensis: Proceedings of the Tenth International Congress of Neo-Latin Studies (Ávila, 4-9 August 1997), Tempe, Arizona: Arizona Center for Medieval and Renaissance Studies: 597-602.

Solana Pujalte, Julián (2012), «Sepúlveda, Juan Ginés de», en J. F. Domínguez Domínguez (ed.), Diccionario biográfico y bibliográfico del humanismo español (siglos XV-XVII), Madrid: Ediciones Clásicas: 773-785.

Solana Pujalte, Julián (2016). «Sebastián de León, secretario de humanistas y aprovisionador de libros», en F. Fuentes Moreno, M. del Castillo Herrera, P. R. Díaz Díaz, C. Hoces Sánchez, M. Molina Sánchez (eds.), Quantus qualisque. Homenaje al profesor Jesús Luque Moreno, Granada: Universidad: 587-598.

Solana Pujalte, Julián (en prensa), «Las ediciones aldinas de la biblioteca de la catedral de Córdoba y el legado de Juan Ginés de Sepúlveda», en Benito Rial Costas (ed.), Manucio en España. La creación de un mito en la Europa del Renacimiento.

Solana Pujalte, Julián, García Pinilla, Ignacio J. (2011), «Erratas y correcciones manuscritas de autor en la traducción latina de la Política de Aristóteles de Juan Ginés de Sepúlveda editada por Michel de Vascosan (París, 1548)», Cuadernos de Filología Clásica. Estudios Latinos 31, 2: 293-309.

Solana Pujalte, Julián, García Pinilla, Ignacio J. (2015), «Erratas y correcciones manuscritas de autor en la traducción latina de la Política de Aristóteles de Juan Ginés de Sepúlveda editada por Michel de Vascosan (París, 1548) (II): los escolios», en J. M. ${ }^{a}$ Maestre Maestre, S. I. Ramos Maldonado, M. A. Díaz Gito, M. ${ }^{a}$ V. Pérez Custodio, B. Pozuelo Calero, A. Serrano Cueto (eds.), Humanismo y Pervivencia del Mundo Clásico, Homenaje al Profesor Juan Gil, V.2, Alcañiz: Instituto de Estudios Humanísticos; Madrid: Consejo Superior de Investigaciones Científicas...: 1019-1036.

Stornajolo, Cosimo (1895), Codices urbinates graeci Bibliothecae Vaticanae, descripti praeside Alfonso cardinali Capecelatro. Recensuit Cosimus Stornajolo. Accedit Index vetus Bibliothecae Urbinatis nunc primum editus, Romae: ex typographeo Vaticano.

Susemihl, Franz (1872), Aristotelis Politicorum libri octo cum vetusta translatione Guilelmi de Moerbeka. Recensuit F. Susemihl, Lipsiae: in aedibus B. G. Teubneri.

Susemihl, Franz, Hicks, Robert D. (1894), The Politics of Aritotle. A revised text with introduction, analysis and commentary by F. Susemihl and R. D. Hicks. Books I-V, London: Macmillan and Co. and N. York. 